\title{
EconomiX
}

\section{Innovation Performance and the Signal Effect: Evidence from a European Program}

Nadine Levratto

Aurélien Quignon

2021-34 Document de Travail/ Working Paper

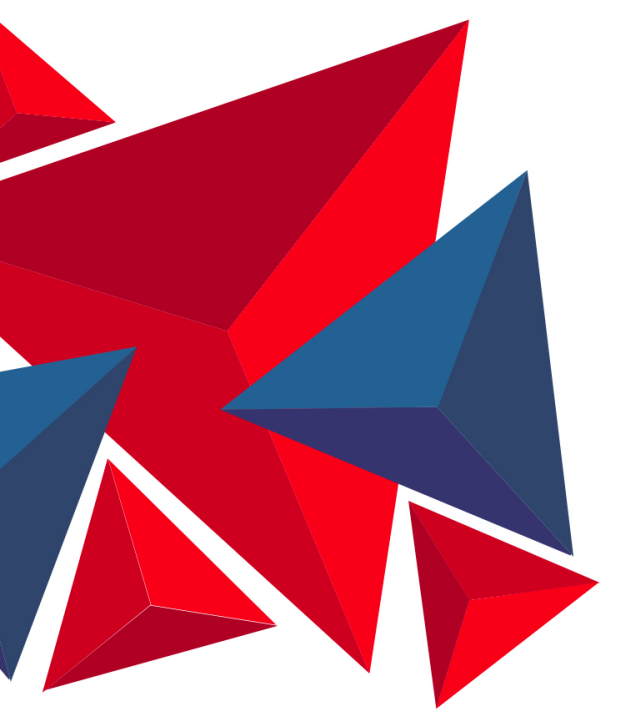

EconomiX - UMR 7235 Bâtiment Maurice Allais

Université Paris Nanterre 200, Avenue de la République 92001 Nanterre Cedex

Site Web : economix.fr Contact : secreteriat@economix.fr Twitter : @EconomixU
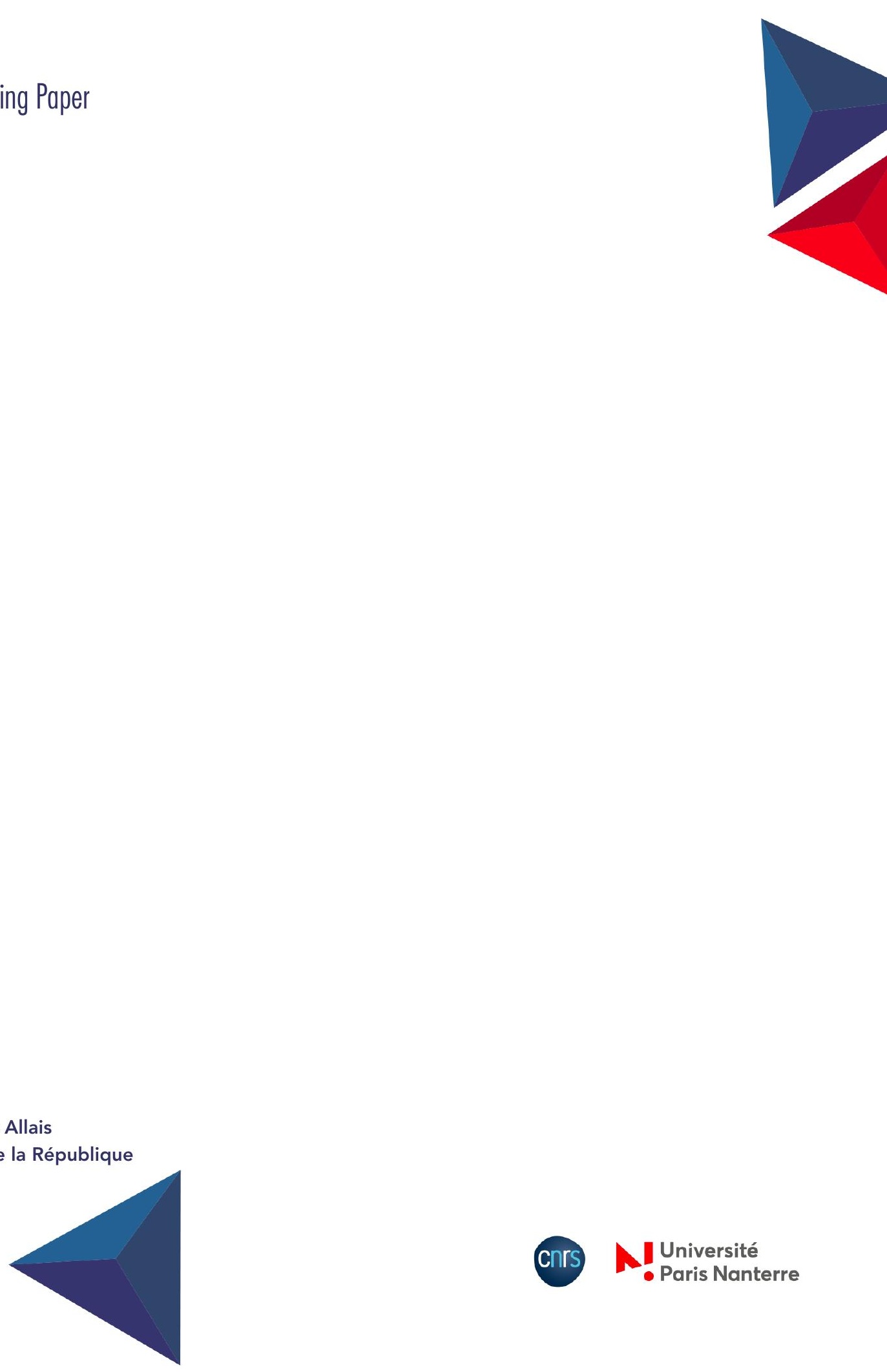


\title{
Innovation Performance and the Signal Effect: Evidence from a European Program
}

\author{
NADINE LEVRATTO and AURELIEN QUIGNON* \\ EconomiX-CNRS UMR 7235, Paris Nanterre University, France
}

\begin{abstract}
This paper seeks to estimate the effect of a European policy that subsidizes innovation investments. By carefully selecting observables, we compare recipients of the program with non-recipient firms to overcome the endogeneity of $\mathrm{R} \& \mathrm{D}$ grants. We conduct a difference-in-differences design on the universe of a unique firm-level dataset of European SMEs between 2008 and 2017. We find a significant effect of proof of concept grants, which implies an increase in the number of patent applications and the probability of patenting. There are positive impacts on credit financing, which suggest a signal effect to investors about the project quality of young firms.
\end{abstract}

JEL classification: G28, G32, O30, O38

Keywords: R\&D subsidies, Innovation, Patent, Financing constraints, H2020

\section{Introduction}

Public support for private research and development $(\mathrm{R} \& \mathrm{D})$ and breakthrough innovations have gained popularity among developed and emerging countries through tax incentives and direct subsidies. Theoretical rationales for $R \& D$ subsidies are that firms cannot fully internalize the social return to $R \& D$, which leads to a suboptimal resource allocation of private R\&D (Arrow, 1962; Nelson, 1959). Another rationale is that $R \& D$ investments face financial constraints reinforced by information frictions and project uncertainty (Hall and Lerner, 2010). Despite the existence and popularity of R\&D subsidies in developed economies, the causal evidence on their efficacy in terms of the crowd-in or crowd-out impact on knowledge production is ambiguous and uninformative (Zúñiga-Vicente et al., 2014). This uncertainty creates a fundamental policy question about whether such programs are successful at boosting innovation performance (Bloom et al., 2019). One major concern is that direct subsidies from selected programs may drive infrastructural investments that would not have occurred without public support. Therefore, the crowd-in effect of direct R\&D subsidies is determined by selecting and monitoring winners by public agencies. Another concern is the absence of exogenous variation in policy intervention and the selection bias caused by the non-randomness of assignment, which amplifies the difficulty of assessing the effectiveness of public support (Cerqua and Pellegrini, 2014; Neumark and Simpson, 2015).

In this paper, we investigate the impact of Horizon 2020 R\&D grants launched in 2014 to directly address the financing gap of creative small and medium-sized enterprises (SMEs) that create new market

\footnotetext{
${ }^{*}$ Nadine Levratto: EconomiX-CNRS 7235, Paris Nanterre University, email: nadine.levratto@parisnanterre.fr, Aurelien Quignon (corresponding author): EconomiX-CNRS 7235, Paris Nanterre University, 200 Avenue de la République, 92001 Nanterre, France, email: a.quignon@ parisnanterre.fr. We are grateful to anonymous referees for their constructive suggestions. We also thank Michele Cincera, Jackie Krafft, Bettina Peters, Maikel Pellens, Jacques Mairesse, Benjamin Monnery, Ilia Samarin, Julien Salin, and seminar and conference participants at the 8th ZEW/MaCCI Conference on the Economics of Innovation and Patenting in Mannheim, the Competition and Innovation summer school in Ulcinj, and Paris Nanterre University (EconomiX) for helpful comments.
} 
ideas. This program's study provides helpful policy recommendations from a larger sectoral and geographic perspective, especially given its design similarities to the Small Business Innovation Research (SBIR) program, through which federal agencies distribute R\&D grants to high-tech firms (Lerner, 2000; Howell, 2017). The SMEI program is divided into two stages. Phase 1 grants assist feasibility and proof of concept initiatives with $€ 50,000$, whereas Phase 2 winners get grants ranging from $€ 500,000$ to $€ 2.5$ million to finance market readiness for breakthrough inventions. European cut-off dates are used to choose applicants based on project quality. At each cut-off, projects are rated by independent experts who provide an overall score, and the projects with the highest-ranking scores are chosen as program winners based on the projected budget. We estimate the effect of R\&D grants by examining changes in the innovation output of recipients and comparable non-recipients over time. To estimate treatment effects and control for potential selection bias in grant allocation, we implement robust estimates by combining propensity score matching (PSM) with a difference-in-difference (DID) estimator because the properties of the two estimators are complementary (Imbens and Rubin, 2015; Blundell and Costa Dias, 2000).

Our findings suggest that proof-of-concept R\&D grants increased the number of patent applications and the likelihood of patenting. Within three years after the grant assignment, the effect continuously increases. Therefore, the proof-of-concept grant has an additionality effect on the patenting of firms, which enables recipient firms to experiment and develop new inventions. By contrast, our findings suggest that R\&D grants awarded for product development in Phase 2 have no significant effect at both the intensive and extensive margins. According to our preferred conditional difference-in-differences for the Phase 1 winners, we provide a back-of-envelope calculation of the direct cost-per-patent. We found a direct cost-per patent in the range of $€ 90,090$ to $€ 101,626$. Also, we explore treatment heterogeneity with respect to the age and size of firms as proxies of ex-ante financial constraints. We find that younger firms (those under 8 years old) are significantly more likely than their counterparts to respond positively to $R \& D$ grants.

What mechanism in treated firms explains the positive response? The impact of the R\&D grant on innovation performance might alleviate financial constraints through a resource (Howell, 2017) or certification effect (Meuleman and De Maeseneire, 2012; Lerner, 2000). We show that the effects of the $R \& D$ grants can be partially explained by the positive effects of the outstanding debt of younger firms, consistent with the certification mechanism that convey information to external investors about the firm's innovative quality. We further show that the resource effect does not appear to be the primary mechanism by showing an insignificant impact on the relative size of the grant. This suggests that a larger grant has the same effect on patenting activities as a smaller grant. The results shed more light on the role of financial constraints and the role of the European program as a signal effect on external investors.

This paper is related to several strands of the literature. First, our paper contributes to the extensive literature on public incentives for R\&D and innovation investments, which addresses policymakers' most pressing concerns (Hutschenreiter et al., 2019). Although there is a growing body of evidence that tax incentives have a positive effect on physical and R\&D investments (Guceri and Liu, 2019; Rao, 2016; Zwick and Mahon, 2017; Dechezleprêtre et al., 2016), the evidence on R\&D subsidies is inconclusive (see for example the meta-study of Dimos and Pugh 2016. ${ }^{1}$ Furthermore, recent studies use firm-level data and compelling causal evidence but focus exclusively on public policies that are limited sectorally or

\footnotetext{
${ }^{1}$ There is a large literature on the effects of $R \& D$ grants on firm outcomes with contrasting results. For example, González et al. (2005), Görg et al. (2008), Czarnitzki and Lopes-Bento (2014), Bronzini and Piselli (2016), Howell (2017), and Le and Jaffe (2017) find a positive impact. In contrast, Wallsten (2000), Lach (2002), Bronzini and Iachini (2014), and Hünermund and Czarnitzki (2019) find on average no positive effects.
} 
geographically (Howell, 2017; Bronzini and Piselli, 2016), limiting the generalizability of the findings. Bronzini and Iachini (2014) and Bronzini and Piselli (2016) focus on the effect of R\&D subsidies on capital investment and patents in Northern Italy in an RD Design using the ranking of a committee of experts and find no effect on investment but significant effects of $R \& D$ grants on patenting. Howell (2017) also uses an RD Design to uncover positive effects on future venture capital funding and patents from the US SBIR program administered by the Department of Energy. Therefore, applicants only represent a small fraction of the program in terms of technologies and budget allocation. We are distinct from these papers by using large and extensive firm-level data in Europe. The SME instrument presents a good case study in that it is the first European program that directly subsidizes SMEs in firms located in 33 countries without restrictions to sectors. ${ }^{2}$ Our results support and complement the positive effects of R\&D subsidies on innovation outcomes.

Second, very few studies examine the impact of grants on multiple aspects of innovation, ranging from increased R\&D investment to innovation outcomes and improved firm performance. Unlike previous findings, we examined the effects on a variety of firm-level performance measures (i.e., firm-level revenues, investment, and employment growth) to provide a more comprehensive understanding of the role of R\&D subsidies in promoting firm growth. We show that the positive effects on innovation outcomes documented by Howell (2017) and Bronzini and Piselli (2016) are also accompanied by increased firm-level revenues, capital investment, and higher firm growth as measured by employees in firms that are more likely to be financially constrained.

Third, our paper contributes to the literature on the consequences of international transfers (for example, Lerner 2000; Howell 2017). The European program is modeled after the US SBIR program, which has been a key source of finance for high growth potential innovative firms for several decades, both for innovation and equity financing. To the best of our knowledge, our findings revealed a program design comparable to the US SBIR, but in a different institutional setting, which enhances policy suggestions in this context. Given the European paradox (e.g., Cincera et al. 2016, which refers to the difficulties of European countries in converting scientific knowledge into marketable inventions, such initiatives are a key issue for policymakers in European countries. In terms of financial options for small and leading entrepreneurs, Europe has typically lagged behind the United States (Cincera et al., 2016; Brown et al., 2009). Therefore, the SME Instrument represents the first scheme implemented in Europe to alleviate debt and equity gaps for young and small innovative firms to bring new ideas to the market.

Finally, this paper refers to the broader literature on financing constraints in the presence of imperfect capital markets, in particular the role of public subsidies in signaling project quality to external investors (Lerner, 2000; Meuleman and De Maeseneire, 2012). Although there is a large literature on financing constraints for innovative firms, most studies have focused on public enterprises and sensitivity to cash flow, evidence on whether public support for SMEs lowers the cost of capital in the European context is scarce. This paper proves that $\mathrm{R} \& \mathrm{D}$ grants provide private signal information.

The remainder of the paper is organized as follows. Section 2 presents the theoretical framework; Section 3 describes the institutional framework and describes the data; we present the identification strategy in Section 4 and, Section 5 report our main results for Phases 1 and 2 as well as robustness tests; Section 6 explores potential mechanisms; finally Section 7 concludes.

\footnotetext{
${ }^{2}$ Until the Horizon2020, the European frameworks for innovation has been focused on collaborative projects between public and private (or private-private) actors, providing funding for transnational innovative projects (Hünermund and Czarnitzki, 2019). For example, the Eurostar program supports innovation through R\&D grants to SMEs consortia from different countries involved in the EUREKA program. Recently, the Fast Track to Innovation (FTI) and the Future and Emerging Technologies (FET) provide funding for consortia between "industry participants" and science (public actors) to stimulate breakthrough, market-creating innovation or radically new technologies across the EU.
} 


\section{Conceptual Framework: R\&D Grant and Capital Market Imperfections}

The main economic rationale for R\&D incentives to private firms (grants, loans, and equity-based instruments) is to overcome two market failures. To begin, according to the literature on innovation, and particularly the argument established by Nelson (1959) and Arrow (1962), R\&D investments produce positive externalities due to the good public character of knowledge. Therefore, other firms can exploit prior R\&D investments to produce new ideas at a lower cost through imitation, and to market new goods to acquire a competitive edge (Hall and Lerner, 2010). Knowledge spillovers lead to incomplete appropriation of the returns from $R \& D$ activities so that the social return to $R \& D$ exceeds the private return. $^{3}$

Second, the literature on financing innovation and investment decisions suggests that capital market imperfections impede innovation investments through a financing gap. Financial frictions are magnified under R\&D projects and innovative investments due to the informational asymmetries that involve a biased evaluation of risky and uncertain projects by external investors. Furthermore, innovative firms lack adequate collateral to pledge. ${ }^{4}$ For these reasons, SMEs are more likely to be credit constrained (Hall and Lerner, 2010; Stiglitz and Weiss, 1981). Several studies point out that this financing gap is more serious for European SMEs. For example, recent evidence shows a negative relationship between R\&D investment and financing constraints in innovative European firms (Hall et al., 2016; Cincera et al., 2016). Cincera et al. (2016) demonstrate that European SMEs lag behind US firms, and this negative effect is exacerbated for young firms. Following in the footsteps of the US SBIR program, the SMEI program seeks to close the financing gap for small and young innovative firms to promote the high growth potential of European SMEs (Howell, 2017).

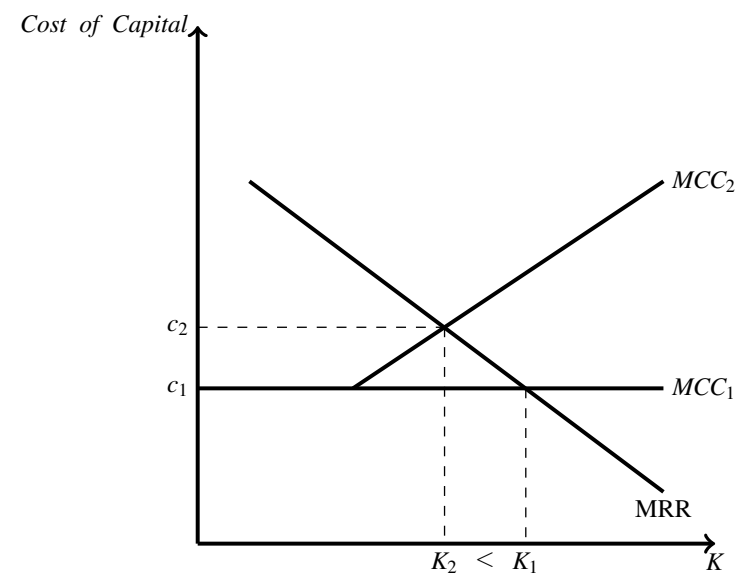

(A) Without Subsidy

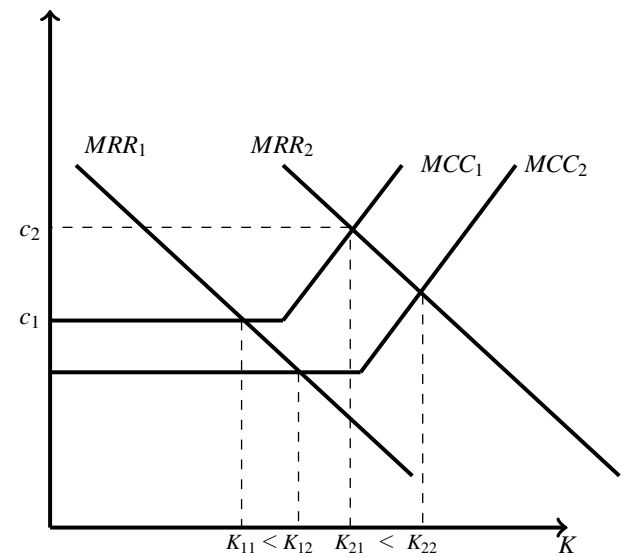

(B) With Subsidy

Figure 1. Impact of R\&D Grant on Cost of Capital.

Note: These figures show the theoretical impact of R\&D grants on the cost of capital for firms facing perfect and imperfect capital markets.

Therefore, what are the possible effects of R\&D subsidies on innovation performance? To illustrate this effect, we first consider a firm-level investment model (e.g., Carpenter and Petersen 2002) that provides a conceptual framework on how R\&D subsidies might affect the innovation performance of SMEs. We compare the situations of firms (without vs. with financial frictions), but without subsidies, and firms

\footnotetext{
${ }^{3}$ For example, Hall et al. (2010) found that private returns to R\&D range from 7 to $15 \%$, while social rates of return range from 30 to $50 \%$.

${ }^{4}$ Since $R \& D$ costs are mainly people such as scientists, it is difficult to provide collateral to borrow on $R \& D$ projects.
} 
that have received a European subsidy, focusing on the cost of capital. Panel A of Figure 1 illustrates the case without subsidy. The level of capital investment $K$ is defined as the intersection of the marginal rate of return (MRR) and the marginal cost of capital (MCC). The downward-sloping MRR curve ranks a firm's projects and investment opportunities. The MCC curve defines the opportunity cost of investment for different stocks of capital $K . \mathrm{MCC}_{1}$ illustrates the case of perfect capital markets, where the firm faces a horizontal cost of capital in that it relies exclusively on internal funds to finance projects. In contrast, the $\mathrm{MCC}_{2}$ curve illustrates the case of imperfect capital markets as upward sloping to the extent that the firm relies on costly external funds. In this case, a firm may be financially constrained if it finances investments with external funds from debt or equity rather than relying on internal funds. In the case without public support and considering perfect capital markets, the capital stock (investment opportunities) is $\mathrm{K}_{1}$ for unconstrained firms, and the cost of capital is $\mathrm{c}_{1}$. Conversely, in the presence of imperfect capital markets, the capital stock is $\mathrm{K}_{2}$ and the cost of capital is $\mathrm{c}_{2}$. Given this toy model, financially constrained firms $\left(\mathrm{MCC}_{2}\right)$ have a lower capital stock $\left(\mathrm{K}_{2}<\mathrm{K}_{1}\right)$ and higher capital costs $\left(\mathrm{c}_{2}>\right.$ $\mathrm{c}_{1}$ ) than firms that rely exclusively on internal funds.

We then turn to the case of firms facing financing constraints and without constraints, but that have received a subsidy. Panel B of Figure 1 illustrates the case of a subsidy. Before receiving a grant, a firm without constraints has an $\mathrm{MRR}_{1}$ that crosses the horizontal part of the $\mathrm{MCC}_{1}$. In contrast, a constrained firm has an $\mathrm{MRR}_{2}$ that crosses the upward part of $\mathrm{MCC}_{1}$ at cost of capital $\mathrm{c}_{2}$ and relies on external funds. The SMEI program has a direct effect on the cost of capital by moving $\mathrm{MCC}_{2}$ downward. For a similar R\&D subsidy, the effect is stronger for financially constrained firms (upward sloping part) than for unconstrained firms (horizontal part). R\&D subsidies (cash shock) induce additional investments $\left(\mathrm{K}_{21}<\right.$ $\mathrm{K}_{22}$ ) greater than $\left(\mathrm{K}_{11}<\mathrm{K}_{22}\right)$ and disproportionately reduce the cost of capital for financially constrained firms. The positive effect may be exacerbated for small and young firms that are more likely to be financially constrained (Czarnitzki and Hottenrott, 2011; Carpenter and Petersen, 2002). In addition, high-tech firms at the frontier may face more severe financial constraints than their counterparts.

Potential mechanisms that may explain the effect on financing constraints could be through resource allocation or a signal effect. Funds are used to invest in a proof of concept and R\&D that demonstrates the quality of the project, which mitigate information asymmetries, and uncertainty about the technology. (Howell, 2017). On the other hand, the program may have an indirect effect that gives recipient firms a certification effect similar to a labour market signal (Spence, 1973). This indirect effect discloses quality information about projects to external investors, which reduces the cost of capital by reducing informational asymmetries between SMEs and investors (Lerner, 2000). Therefore, the conceptual framework provides a rationale for public support and the mechanisms underlying the effect on firms' innovation. We can predict that R\&D subsidies can have an effect on financially constrained SMEs by reducing the user cost of capital.

\section{Institutional Framework and Data}

\subsection{Program Overview}

The SME Instrument (SMEI) is a selective public program for European start-ups and SMEs. It is a joint initiative of the European Innovation Council (EIC) and the European Commission (EC). The program is part of the Eighth Framework Program Horizon $2020^{5}$, which was adopted on December 10, 2013, by

\footnotetext{
${ }^{5}$ European Union has started to focus on research and innovation excellence by introducing structural framework as early as 1982. The first European research agenda, namely Framework Programme (FP1) dedicated to science and technology excellence was introduced in 1984 covering three years (1984-1987).
} 
the EC and officially launched in 2014, and is currently the largest SME public support in Europe. The formal objective of SMEI is to support innovation and market proximity activities, thus improving job creation and productivity growth in Europe. This European program is the first policy dedicated to SMEs to directly support radical ideas and bring them to market. Previously, innovation policies were designed based on cooperation schemes between public and private actors, through consortia.

The program offers financial assistance, mentorship, and networking opportunities to SMEs with high growth potential and marketable ideas in existing and emerging markets. The initial cut-off occurred in June 2014 and will continue until November 2017. Approximately $€ 1.31$ billion have been given to 3208 program winners out of a total of 46,772 program applications in the 33 countries engaged $^{6}$, with $€ 250$ million distributed in 2014.

\subsection{Eligibility and Selection Process}

The SMEI is mainly designed on the largest R\&D subsidies program that occurs in the US, namely, the Small Business Innovation Research Program (SBIR), and comprises three independent phases. Figure 2 presents a schematic of the selection steps, which are described and summarized in this section.

Phase 1 is a proof of concept phase that determines the viability of the innovative idea. The objective of Phase 1 is to produce a sound business strategy that considers innovation and project risks. Phase 1 provides a one-time lump sum payment of $€ 50,000$. The investment lasts six months and may encourage the recipient firm to apply for the program's second phase. Phase 2 relates to the forward stage, during which SMEs focus on R\&D activities, prototyping, and demonstration, intending to induce innovation and commercialization. The funding amount varies between $€ 500,000$ to $€ 2.5$ million for each project. The award covers $70 \%$ of the total projected investment expenditure for both stages. The investment period might be substantially longer than in Phase 1 and can range from one to two years. Finally, Phase 3 is an accelerated procedure to improve invention commercialization. However, only a tiny percentage of SMEs (1\%) reach this level. As a result, we omit this phase from our assessment study to concentrate solely on the first two stages of the SMEI program.

The SMEI program is based on a competitive scheme so that projects are granted after a selection and evaluation process. Thus, applicants submit a business plan that will be evaluated by four independent and specialized experts named by the Executive Agency for SMEs (EASME). The submitted business plan is scored on the three distinct criteria of (i) impact, (ii) excellence and (iii) the quality and efficiency of the implementation with a score that ranges between 0 and 5 for each criterion, which gives a maximum score of 15 for a proposal. ${ }^{7}$ The program is selective since R\&D funding is granted conditionally up to a certain amount, and only the top-ranking proposals are chosen at each cutoff. The threshold for Phase 1 is 13 , with a minimum value of 4 for each criterion. In comparison, the threshold in Phase 2 is 12, with a minimum of 4 for the effect criterion and 3 for the remaining two criteria. This selection procedure guarantees that the best business proposals in terms of innovation potential are chosen.

Panel B of Appendix Table A.1 summarizes the treatment group for our analysis sample of program winners in the first cutoff ${ }^{8}$ (2014) from ten European countries. This gives a total of 594 program winners

\footnotetext{
${ }^{6}$ Countries under the SME instrument included: Austria, Belgium, Bosnia and Herzegovina, Bulgaria, Croatia, Cyprus, Czech Republic, Denmark, Estonia, Finland, France, Germany, Greece, Hungary, Iceland, Ireland, Israel, Italy, Latvia, Lithuania, Luxembourg, Macedonia, Malta, Moldova, Netherlands, Norway, Poland, Portugal, Romania, Serbia, Slovakia, Slovenia, Spain, Sweden, Turkey, the United Kingdom.

${ }^{7}$ The overall score is based on the median score giving by each evaluator.

${ }^{8}$ In 2014, a total of 4 cut-offs was introduced. The distribution of the cut-off dates was as follows, the first cut-off date was in June 2014, the second in September 2014, the third in October 2014 and the last deadline was in December 2014. However,
} 


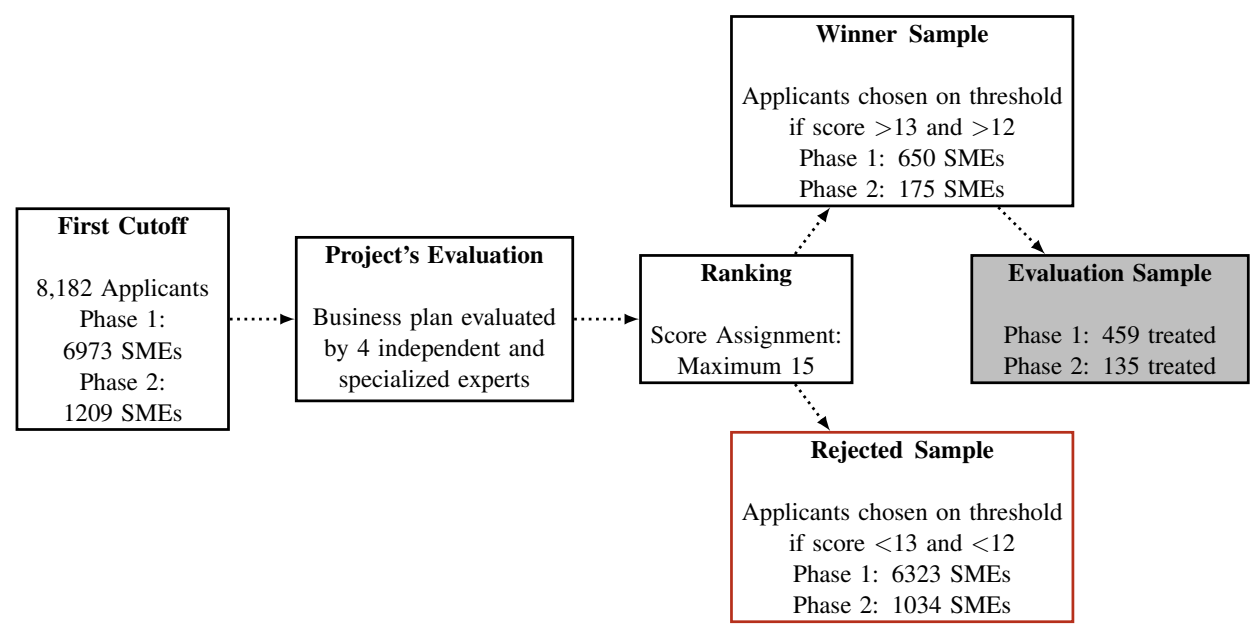

Figure 2. Program Stages and Timing of the Investment.

Note: This figure shows the program steps in the first cut-off year (2014) and R\&D grant assignment for chosen innovative projects.

divided between 459 and 135 firms in Phases 1 and 2, respectively.

\subsection{Data and Sample Construction}

We combine five distinct datasets to construct our main analysis sample of innovative firms. In particular, we match EASME data with the Bureau Van Dijk's Amadeus dataset, PATSTAT and Crunchbase. The resulting sample is an unbalanced panel of the population of the SMEI program's winners and European innovative firms, which consists of 454,247 firm-year observations from 2008 to 2017.

The EC provides the EASME database, which is used to supervise Horizon 2020 projects. The database contains detailed information on all program winners since 2014, including the firm's identifier and address, a brief project description, the objective, the amount applied for, the amount of the R\&D grant, and the participation phase. EASME allows for the identification of recipient firms and divides the analysis into two phases: proof of concept (Phase 1) and development and commercialization (Phase 2), but not firm characteristics or results at the firm level. Without access to cross-national administrative data, Amadeus has the largest coverage of cross-national firm-level data (Autor et al., 2020). Consequently, we match the program winners with the data from Amadeus that contains all European balance sheet information reports to tax authorities or data collection agencies. This allows us to match over 70 percent of all the SMEI program winners, which covers the period from 2008 to 2017. Non-matched firms are mostly due to a lack of available information on the analysis period in Amadeus. ${ }^{9}$ The resulting sample, which refers to recipient firms, contains 4,110 firm-year observations, with 3,310 and 870 firmyear observations from Phases 1 and 2, respectively. The control group consists of European SMEs that have never received grants from the SMEI program. Specifically, from Amadeus, we randomly selected a sample of SMEs located in the ten European countries covered by our analysis from the entire firm population and merged balance sheet data. The following criteria are used to select our control group. To begin, the SMEI program eligibility rules apply to businesses with fewer than 250 employees and a

\footnotetext{
only two cut-off dates were available for applicants firms to Phase 2 (October and December).

${ }^{9}$ Appendix Tables A.2 and A.3 compare the sample of Amadeus-matched firms to the missing recipient firms. To assess the representativeness of the matched firms, we also report the standardized mean differences between the analysis sample and the recipient firms. Except for a few variables, the results indicate that the observable characteristics are similar (below the 0.25 threshold). These findings reassure us of the representativeness of our sample for analysis.
} 
turnover and balance sheet of less than $€ 50$ million and $€ 43$ million, respectively. Second, the SMEI program includes firms with a high potential for innovation and growth and breakthrough ideas, and close-to-market innovation. As a result, a firm is considered innovative if it has a patented invention in one jurisdiction. ${ }^{10}$ The resulting sample, referred to as the potential control group, includes 432,470 firm-year observations from 2008 to 2017.

We also use Amadeus to measure firm-level characteristics that we use in our analysis to control whether or not a firm is likely to apply and receive public support. The observable characteristics include country location, one-digit industry classification code (NACE Rev.2), firm age, size, intangible and tangible assets, and the patent stock. Size is proxied by the natural logarithm of total assets owned by firm. ${ }^{11}$ Total assets equal total book assets. Intangible assets are measured as the natural logarithm of the total of intangible products with a useful life, with an amortization that includes goodwill, software, research and development expenditure, and intangible rights. Tangible assets are measured as the natural logarithm of the total physical assets that equals the book value of all tangible capital assets owned by the firm.

Table 1 shows the summary statistics for the sample of the treated group and the randomly selected control group based on the assignment of treatment status. We observe that firms that recipient firms are 8 years younger than non-recipient, are 21 percent larger ( $€ 1,019,680$ versus $€ 842,391$ total assets), have higher stock of intangible capital.

Patents is proxy for innovation outcome. Patenting activities are very reliable for the economic value of knowledge and firm performance. We match patents to firms based on the firm name and the accounts for name changes using PATSTAT. We also use the matching operation between PATSTAT and Amadeus to avoid missing patent assignments, and we check the matching quality manually. Separate analyses are conducted for the intensive and extensive margin responses. First, the intensive margin variable is the number of patent applications (Patent) filed with the EPO, USPTO, and PCT via WIPO. To control for the heterogeneous value of patents, we only use applications to major offices as these patents are likely to be of higher value (Dechezleprêtre et al., 2016). Moreover, considering these international patent applications instead of patent applications at national offices has the advantage of avoiding the enforcement bias and the specific criteria required to patent an invention in national jurisdictions. Second, we measure the extensive margin variable (Appl) using a dummy variable that is equal to one for patent applications and zero otherwise. ${ }^{12}$ On average, treated firms filed 0.223 patents, while the control group tended to file on average fewer patents (0.121). We also define the patent stock as the cumulative number of patent applications. The treated group experienced higher innovation capacity with an average cumulative number of patent applications of 0.436 more than the control group.

Finally, we match private financing events from Amadeus and Crunchbase to the treated and control observations. We measure debt finance, differentiated between short- and long-term debt to test whether grants convey valuable information to external investors. Debt financing is a sign of investment potential and commercial success. Crunchbase also provides data on governmental subsidies obtained from various European-based initiatives that support SMEs' innovation. ${ }^{13}$

\footnotetext{
${ }^{10}$ Defining innovation capacity with patent measures may seem restrictive because not all patenting firms conduct R\&D investments, but there are inventions without R\&D (Boeing, 2016).

${ }^{11}$ For Size, Intangible Assets and Tangible Assets variables, we applied the inverse hyperbolic sine transformation $f(x)=\log \left(x+\left(x^{2}+1\right)^{1 / 2}\right.$, because of negative values reported in company accounts.

${ }^{12}$ We use applications rather than the number of patents granted because applications are closer to the time of invention, mitigate potential truncation problems in our sample due to the length of the examination process, and improve our coverage rates in the post-intervention period (Bronzini and Piselli, 2016). We also use information from patent families to avoid double counting for the same invention.

${ }^{13}$ Under the analysis period cover, multiple initiatives for SMEs were launched both under the Framework Programme
} 
Table 1. Summary Statistics

\begin{tabular}{|c|c|c|c|c|c|}
\hline \multirow[b]{2}{*}{ Variables } & \multicolumn{2}{|c|}{ Treated Group } & \multicolumn{2}{|c|}{ Control Group } & \multirow[b]{2}{*}{ Diff } \\
\hline & Mean & S.D & Mean & S.D & \\
\hline \multicolumn{6}{|l|}{ Outcomes variables: } \\
\hline Patent & 0.223 & 1.552 & 0.121 & 1.659 & $* * *$ \\
\hline Patent pre- $R \& D$ grant & 0.229 & 1.878 & 0.123 & 1.853 & $* * *$ \\
\hline Patent post-R\&D grant & 0.213 & 0.858 & 0.117 & 1.314 & $* * *$ \\
\hline Patent EPO & 0.081 & 0.656 & 0.052 & 0.746 & $* * *$ \\
\hline Patent WO & 0.061 & 0.385 & 0.041 & 0.695 & $*$ \\
\hline Patent US & 0.079 & 0.774 & 0.027 & 0.357 & $* * *$ \\
\hline Appl & 0.079 & 0.270 & 0.061 & 0.240 & $* * *$ \\
\hline \multicolumn{6}{|l|}{ Control variables: } \\
\hline Age & 9.758 & 10.714 & 17.480 & 18.502 & $* * *$ \\
\hline Size $(\log )$ & 13.835 & 2.301 & 13.644 & 1.905 & $* * *$ \\
\hline Intangible Assets (log) & 6.666 & 6.215 & 4.854 & 5.199 & $* * *$ \\
\hline Tangible Assets (log) & 11.441 & 2.577 & 11.474 & 2.308 & - \\
\hline Patent Stock & 0.436 & 2.328 & 0.130 & 2.284 & $* * *$ \\
\hline \multicolumn{6}{|l|}{ Sector: } \\
\hline Agriculture, forestry and fishing & 0.004 & 0.069 & 0.015 & 0.153 & $* * *$ \\
\hline Manufacturing, mining and quarrying and other industry & 0.036 & 0.186 & 0.034 & 0.180 & - \\
\hline Construction & 0.254 & 0.435 & 0.258 & 0.438 & - \\
\hline Wholesale and retail trade, transportation and storage & 0.062 & 0.242 & 0.065 & 0.246 & - \\
\hline Information and communication & 0.065 & 0.246 & 0.224 & 0.417 & $* * *$ \\
\hline Financial and insurance activities & 0.024 & 0.153 & 0.014 & 0.117 & $* * *$ \\
\hline Real estate activities & 0.136 & 0.343 & 0.157 & 0.368 & $* * *$ \\
\hline Professional, scientific, technical service activities & 0.368 & 0.482 & 0.173 & 0.378 & $* * *$ \\
\hline Public administration, defence, education activities & 0.043 & 0.203 & 0.044 & 0.204 & - \\
\hline Other services & 0.007 & 0.084 & 0.016 & 0.126 & $* * *$ \\
\hline Sample Size: & \multirow{2}{*}{\multicolumn{2}{|c|}{418}} & \multirow{2}{*}{\multicolumn{2}{|c|}{43,247}} & \\
\hline Joint Orthogonality Test: & & & & & \\
\hline
\end{tabular}

Notes: This table presents summary statistics for the treated and control group. The treated group is composed of program winners in Phase 1 and 2, while the control group is composed of randomly drawn sample of European SMEs. The last column reports the difference for each variable (the t-test of equal mean) across two groups. $* p<0.1, * * *$ $p<0.01$

Overall, the observed differences in the average observable characteristics suggest that the treatment is not randomly assigned and might reflect selection bias. We formally test the randomization of the treatment through an $F$-test of joint orthogonality that tests whether observable characteristics are unrelated to the R\&D grant assignment. We reject the null hypothesis (i.e., $p$-value $=0.000$ ) that the observable characteristics of the treated group are unrelated to these characteristics of the control group.

\section{Empirical Strategy}

\subsection{Identification Strategy}

We emphasize that we reject that the observable characteristics are similar across groups, as suggested in Table 1. In R\&D subsidy evaluations, this problem refers to selection bias in the treatment evaluation

7 (FP7) and Horizon 2020. These support programs follow a bottom-up approach and encompass the following programs: Eureka-Eurostars, Fast Track to Innovation (FTI), and Future and Emerging Technologies (FET). 
Table 2. Balancing Tests

\begin{tabular}{|c|c|c|c|c|c|c|}
\hline \multirow[b]{2}{*}{ Covariates } & \multicolumn{3}{|c|}{ Phase 1} & \multicolumn{3}{|c|}{ Phase 2} \\
\hline & $\begin{array}{l}\text { Recipient } \\
\text { Firms } \\
\text { Mean }\end{array}$ & $\begin{array}{l}\text { Non-recipient } \\
\text { Firms } \\
\text { Mean }\end{array}$ & Diff & $\begin{array}{l}\text { Recipient } \\
\text { Firms } \\
\text { Mean }\end{array}$ & $\begin{array}{l}\text { Non-recipient } \\
\text { Firms } \\
\text { Mean }\end{array}$ & Diff \\
\hline \multirow[t]{2}{*}{ Age } & 11.980 & 12.415 & 0.434 & 13.039 & 13.934 & 0.874 \\
\hline & $(0.627)$ & $(0.582)$ & $(0.082)$ & $(1.298)$ & (1.109) & $(1.708)$ \\
\hline \multirow[t]{2}{*}{ Size } & 13.972 & 13.933 & -0.039 & 14.733 & 14.913 & 0.179 \\
\hline & $(0.108)$ & $(0.092)$ & $(0.142)$ & $(0.180)$ & $(0.166)$ & $(0.245)$ \\
\hline \multirow{2}{*}{ Intangible Assets } & 8.196 & 8.371 & 0.174 & 9.131 & 9.201 & 0.069 \\
\hline & $(0.345)$ & $(0.312)$ & $(0.465)$ & $(0.667)$ & $(0.655)$ & $(0.935)$ \\
\hline \multirow[t]{2}{*}{ Tangible Assets } & 11.026 & 11.103 & 0.076 & 11.692 & 11.977 & 0.285 \\
\hline & $(0.166)$ & $(0.163)$ & $(0.233)$ & (0.269) & $(0.362)$ & $(0.452)$ \\
\hline \multirow[t]{2}{*}{ Patent Stock } & 0.193 & 0.193 & 0 & 0.644 & 1.026 & 0.381 \\
\hline & $(0.040)$ & $(0.052)$ & $(0.066)$ & $(0.187)$ & $(0.537)$ & $(0.569)$ \\
\hline \multirow[t]{2}{*}{ Agriculture, forestry and fishing } & 0.003 & 0.003 & 0 & 0.013 & 0.013 & 0 \\
\hline & $(0.003)$ & $(0.003)$ & (0.004) & (0.013) & (0.013) & $(0.018)$ \\
\hline \multirow{4}{*}{$\begin{array}{l}\text { Manufacturing, mining and } \\
\text { quarrying and other industry } \\
\text { Construction }\end{array}$} & 0.046 & 0.042 & -0.003 & 0.026 & 0.026 & 0 \\
\hline & $(0.012)$ & $(0.012)$ & $(0.017)$ & $(0.018)$ & (0.018) & $(0.026)$ \\
\hline & 0.243 & 0.320 & 0.077 & 0.342 & 0.381 & 0.039 \\
\hline & $(0.025)$ & (0.028) & $(0.037)$ & $(0.055)$ & $(0.056)$ & $(0.078)$ \\
\hline \multirow{4}{*}{$\begin{array}{l}\text { Wholesale and retail trade, } \\
\text { transportation and storage } \\
\text { Information and communication }\end{array}$} & 0.081 & 0.070 & -0.011 & 0.013 & 0.039 & 0.026 \\
\hline & $(0.016)$ & $(0.015)$ & $(0.022)$ & $(0.013)$ & $(0.022)$ & $(0.026)$ \\
\hline & 0.067 & 0.070 & 0.003 & 0.066 & 0.026 & -0.039 \\
\hline & $(0.015)$ & $(0.015)$ & $(0.021)$ & (0.029) & (0.018) & $(0.034)$ \\
\hline \multirow[t]{2}{*}{ Financial and insurance activities } & 0.028 & 0.035 & 0.007 & 0.013 & 0 & -0.013 \\
\hline & (0.009) & $(0.011)$ & $(0.015)$ & $(0.013)$ & $(0.000)$ & $(0.013)$ \\
\hline \multirow{2}{*}{ Real estate activities } & 0.116 & 0.095 & -0.021 & 0.132 & 0.118 & -0.013 \\
\hline & (0.019) & $(0.017)$ & $(0.026)$ & (0.039) & $(0.037)$ & $(0.054)$ \\
\hline \multirow{6}{*}{$\begin{array}{l}\text { Professional, scientific, } \\
\text { technical service activities } \\
\text { Public administration, defence, } \\
\text { education activities } \\
\text { Other services }\end{array}$} & 0.370 & 0.335 & -0.035 & 0.329 & 0.355 & 0.026 \\
\hline & (0.029) & $(0.028)$ & $(0.040)$ & $(0.054)$ & $(0.055)$ & $(0.077)$ \\
\hline & 0.035 & 0.021 & -0.014 & 0.066 & 0.039 & -0.026 \\
\hline & $(0.011)$ & (0.009) & $(0.014)$ & (0.029) & $(0.022)$ & $(0.036)$ \\
\hline & 0.011 & 0.007 & -0.003 & - & - & - \\
\hline & $(0.006)$ & $(0.005)$ & $(0.008)$ & - & - & - \\
\hline Obs. & 2,840 & 2,840 & & 760 & 760 & \\
\hline
\end{tabular}

Notes: For readability, country dummies are not reported. Columns 3 and 6 reports the differences in the mean between the treated and control group. Robust standard errors are reported in parentheses.

literature that can be expressed as follows:

$$
\begin{gathered}
E\left[Y_{i}^{T} \mid \text { Recipient }_{i}=1\right]- \\
-E\left[Y_{i}^{C} \mid \text { Recipient }_{i}=0\right]=\underbrace{E\left[Y_{i}^{T}-Y_{i}^{C} \mid \text { Recipient }_{i}=1\right]}_{\text {Causal Effect }^{E}}+ \\
\underbrace{\left[E\left[Y_{i}^{C} \mid \text { Recipient }_{i}=1\right]-E\left[Y_{i}^{C} \mid \text { Recipient }_{i}=0\right]\right]}_{\text {Selection Bias }}
\end{gathered}
$$

where $\mathrm{Y}^{T}$ and $\mathrm{Y}^{C}$ are potential outcomes conditional on treatment status, which cannot be directly observed in the control group (Recipient $\left.{ }_{i}=1\right){ }^{14}$ Assuming that the mean outcome of the counterfactual situation equals the mean outcome of the non-recipient firms will lead to biased estimates if the grant is not allocated randomly. We follow Blundell and Costa Dias (2000) who argue that the combination of matching procedure with a difference-in-differences estimator provide robust results. This empirical strategy, therefore, controls selection bias as well as time-invariant unobservable firm heterogeneity. To this end, we adopt a conditional difference-in-differences approach (Blundell and Costa Dias, 2000; Heckman et al., 1998).

\footnotetext{
${ }^{14}$ To overcome the selection bias, the propensity score matching relies on the conditional independence assumption (CIA), which stipulates that for a set of observable characteristics exogenous to the treatment assignment, potential outcomes are independent (Rubin, 1974).
} 
Matching on the Propensity Score - We use propensity score matching, which consists of two steps, to overcome selection bias caused by non-random grant allocation. First, a rich set of observable characteristics is used to estimate the probability of treatment for both treated and untreated firms. Second, the two groups are matched based on the propensity score to create a control group that is similar to the treated firms in terms of observable characteristics in the year preceding grant allocation. To condition observable characteristics, we use a nearest-neighbor propensity score matching procedure without replacement in the year preceding the award of the R\&D grant, separately for Phases 1 and 2. To ensure overlap between groups, the matching is supplemented with a common support restriction.

The propensity score is implemented by estimating a logit model for the probability of awarding $R \& D$ grants $\mathrm{P}\left(\mathrm{X}_{i}\right)$, conditional on observable characteristics $\mathrm{X}_{i}$ : country location, industry classification, firm age, size, stock of intangible and tangible assets, and patent stock. We use lagged observable characteristics, except for country location, industry classification, and firm age, to avoid endogeneity between treatment assignment and changes in firm characteristics (Boeing, 2016). This set of observable variables reflects the characteristics of firms applying for the European program as well as the eligibility criteria for obtaining one of the two phases of the program (Mina et al., 2020). This program's main goal is to support radical ideas and the technological capabilities of start-ups and small firms. As a result, we control for innovation intensity by including intangible assets that are associated with firms' innovative capabilities (Bronzini and Iachini, 2014; Czarnitzki and Lopes-Bento, 2013) and patent stock, which allows us to control for the effect of being a patent-active firm. Mina et al. (2020) found that patent applications increase the likelihood of receiving a grant in Phase 1. We also add the firm's size and age, controlling for the fact that the program targets small and young firms, which is consistent with the results of Mina et al. (2020), who found a positive effect of size and a negative effect of age on the probability of program application. In addition, it is often argued that older firms are more reluctant to pursue innovation and would therefore be less likely to apply. Finally, we control for tangible assets that are related to growth performance. Firms that have more tangible capital may have higher collateral to pledge than others, facing lower financing constraints and, hence, less likely to apply for subsidies. Appendix Table A.4 reports the estimated logit specification.

To create a control group, we use nearest-neighbor matching based on the predicted propensity score. The goal of this approach is to match all treated firms with the most similar control firms. A common support constraint is added to the matching. As a result, a total of 26 (respectively 11) observations were removed from the sample of treated firms due to the joint Phase 1 (respectively 2) support. Appendix A.4 and Figure A.2 present the estimated probability of treatment and the distribution of propensity scores across the two groups.

Matching Quality - Balancing tests compare differences in observable features between the treatment group and the matched counterfactual group to determine matching quality. Table 2 shows the results of the balance tests for Phases 1 and 2. The treatment and the counterfactual groups are comparable in terms of average observable characteristics, according to the matching, with minor and non-statistically significant differences. In addition, we conduct robustness tests of our matching procedure. We reestimate the probability of awarding R\&D grants with a matched sample to ensure that no observable characteristics explain the probability of treatment. Appendix Table A.4 shows the estimated logit specification before and after matching. For Phases 1 and 2, all characteristics are statistically insignificant on the corresponding sample with a Pseudo-R-squared significantly reduced from 0.3 (respectively 0.25 ) to 0.01 (respectively 0.04) in Phase 1 (respectively 2). As a result, the characteristics of the firm are well balanced, and the treatment is conditionally randomized to this set of observable characteristics and 
controls for observable heterogeneity between the two groups.

The resulting unbalanced samples yield 2,840 and 760 observations over the treatment group and 2,840 and 760 observations over the counterfactual group in Phases 1 and 2, respectively.

\subsection{Difference-in-differences}

Our main objective is to estimate the causal effect of the SMEI program on innovation performance. Based on the matching and according to the treatment status for recipient and non-recipient firms, our empirical strategy implements a difference-in-differences (DID) specification:

$Y_{i t}=\beta_{0}+\beta_{1}$ Recipient $_{i} \times$ Post $_{- \text {Grant }_{i t}}+\eta_{i}+\delta_{t}+\varepsilon_{i t}$

where $\mathrm{Y}_{i t}$ is the result at firm level $i$ in calendar year $t$. Recipient ${ }_{i}$ is the key policy intervention variable that designates the R\&D grant award status, which is equal to one for recipient firms and zero otherwise. Post-Grant ${ }_{i t}$ is equal to one for years 2014 onward, and zero otherwise. We include firm fixed effects $\eta_{i}$ and time effects $\delta_{t}$ that control for time-invariant unobserved firm heterogeneity in selective participation in the program and aggregate country characteristics. ${ }^{15}$ Because the treatment is defined at the firm level, we cluster the standard errors at the firm-level. ${ }^{16}$ The number of patent applications is a count variable, with a usually asymmetric distribution on the left associated with a long right tail. Therefore, OLS estimates could be biased because the distribution of the count data does not match the normal distribution of the error terms in a log-linear specification. We use the Poisson Quasi-Maximum Likelihood (PQML) estimator (Gourieroux et al., 1984; Guceri and Liu, 2019).

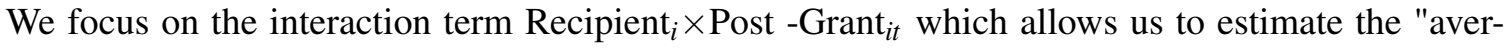
age treatment effect on the treated" (ATET). In other words, this interaction term captures the change in outcomes between pre-and post-intervention for recipient firms relative to non-recipient firms. Recent results from the Bronzini and Iachini (2014), Bronzini and Piselli (2016) and Howell (2017) discontinuity regression plan, which uses treatment variation around a threshold and estimates the local average treatment effect (LATE). In fact, their LATE may be larger than the OLS, which is consistent with the fact that their specification estimates the impact of R\&D subsidies on firm performance in the compliant population, raising concerns about external validity (Imbens and Lemieux, 2008). In contrast, our empirical framework uses the whole treated firms as well as the dynamics of the effect. Furthermore, our identification strategy allows us to control for potential unobserved characteristics or heterogeneity of firms prior to the program, which could lead to an overestimation of the effect of R\&D subsidies (Dimos and Pugh, 2016). This is important for innovation outcomes because of the well-known persistence of innovative activities.

A natural experiment would have been to examine the exogenous assignment of R\&D grants between program winners and the firms for which the business plan was rejected and then estimating the causal relationship between R\&D grants and innovation propensity. Our data do not allow us to observe program-rejected applicants and implicitly, the score assigned to each project. Without randomization, our identification strategy relies on a matching procedure. However, the validity of our DID specifica-

\footnotetext{
${ }^{15}$ We also include country-by-year, 2-digit industry-by-year fixed effects to account for heterogeneity across countries and industries. Unreported robustness tests that include these fixed effects produce qualitatively similar results across all specifications.

${ }^{16}$ Consistent with the literature, we present results clustered at the firm-level (e.g., Zwick and Mahon 2017; Guceri and Liu 2019). However, following the argument of Bertrand et al. (2004), in the presence of a serial correlation in the result, standard errors at the individual level could be biased even with clustering, leading to an overrejection of the null hypothesis of no causal effect. In robustness tests, our results are robust to permutation tests (Ohrn, 2018; Chetty et al., 2009).
} 


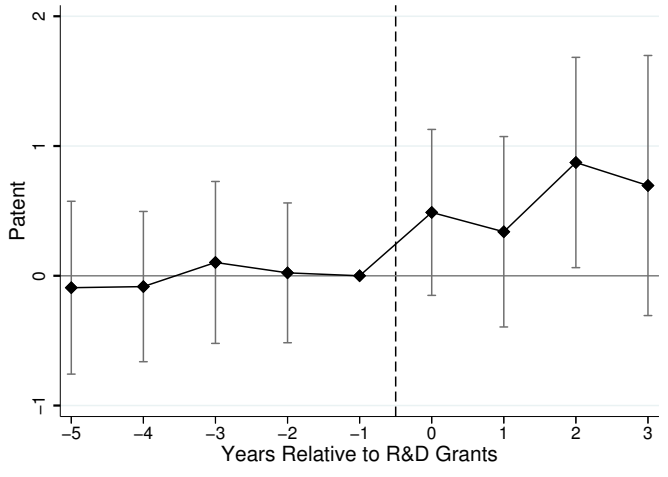

(A) Phase 1: Patent

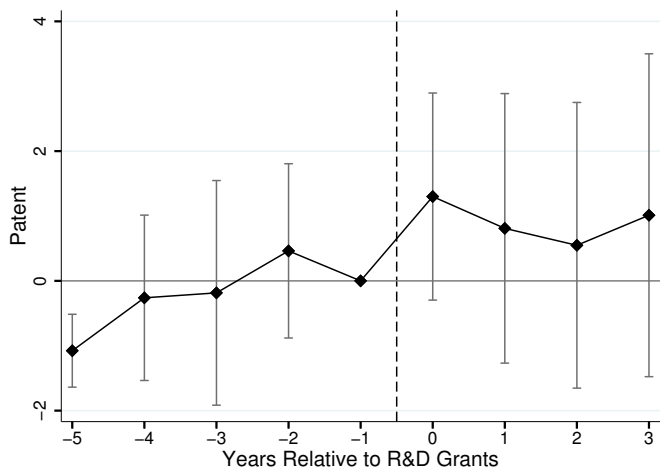

(C) Phase 2: Patent

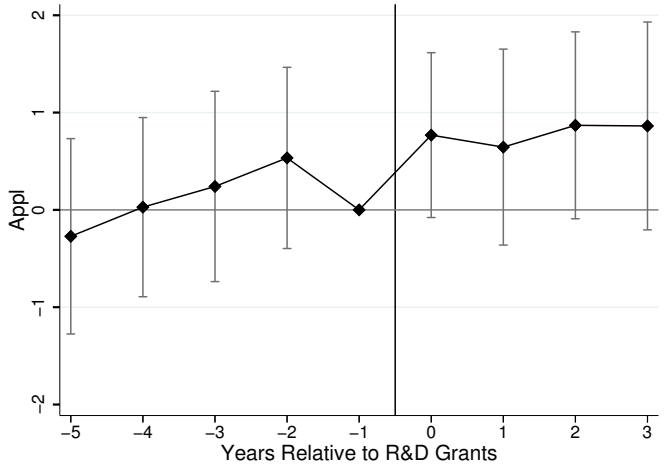

(B) Phase 1: Appl

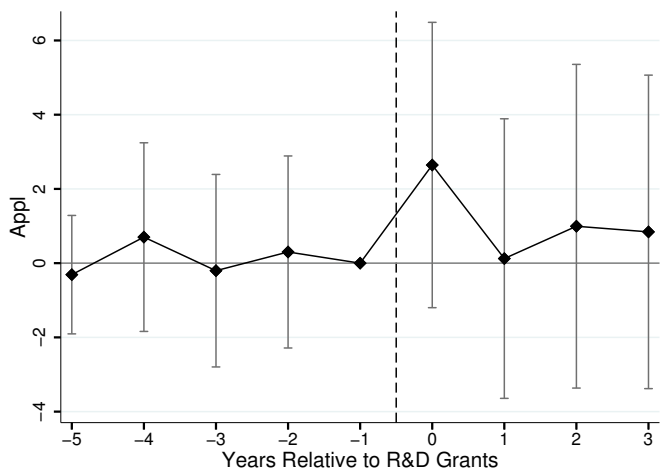

(D) Phase 2: Appl

Figure 3. Event Time Difference-In-Differences Estimates: Pre-Trends Tests.

tion relies on the parallel trends assumption that in the absence of policy intervention, the non-recipient firms would have followed the same path than the recipient firms. To formally confirm the validity of the identification strategy, we implement an event study around the policy intervention, which allows us to use the null hypothesis of no pre-trends (Guceri and Liu, 2019). To address this concern, we implement the following specification:

$Y_{i t}=\beta_{0}+\sum_{t=2008}^{2017} \beta_{t}\left[\right.$ Recipient $_{i} \times \mathbb{1}\left[\right.$ Year $\left.\left._{t}\right]\right]+\eta_{i}+\delta_{t}+\varepsilon_{i t}$

where Recipient ${ }_{i}$ is interacted with time year effects (we include a set of lags and leads around the policy intervention), and the interacted coefficient is normalized to 0 in 2013. Thus, the estimated effects $\beta_{t}$ are relative to the year prior to the policy intervention.

Figure 3 reports the estimated coefficients on this set of leads and lags through specification (3) estimated by logit and PQML. ${ }^{17}$ They are interpreted as changes in the recipient firms' number of patent applications (i.e., the intensive margin) and the probability of patenting (i.e., the extensive margin) relative to the non-recipient firms compared to the period until five years before the implementation of the SMEI program. The point estimates on the intensive and extensive margin responses to the program show that there are no clear pre-trends for both Phases 1 and 2 before the R\&D grants assignment. One exception is the point estimates for the number of patent applications for Phase 2 estimated from PQML

\footnotetext{
${ }^{17}$ Note that we do not report the corresponding figure for OLS regression, but the visual evidence are similar to logit and PQML specifications. Results are available upon request.
} 
Table 3. The Effect of Phase 1 and 2 on Innovation Performance

\begin{tabular}{|c|c|c|c|c|}
\hline \multirow[b]{2}{*}{ Dependent variable: } & \multicolumn{2}{|c|}{$\overline{\text { OLS }}$} & \multirow{2}{*}{$\begin{array}{c}\text { Poisson } \\
\text { (3) Patent }\end{array}$} & \multirow{2}{*}{$\begin{array}{c}\text { logit } \\
\text { (4) Appl }\end{array}$} \\
\hline & (1) Patent & (2) Appl & & \\
\hline \multirow{3}{*}{ Recipient $\times$ Post-Grant } & \multicolumn{4}{|c|}{ Panel A. Phase 1} \\
\hline & $0.106^{*}$ & $0.046^{* *}$ & $0.555^{* *}$ & $0.661 * *$ \\
\hline & $(0.062)$ & $(0.017)$ & $(0.257)$ & $(0.283)$ \\
\hline Obs. & 5,015 & 5,015 & 1,697 & 1,677 \\
\hline Clusters (firms) & 568 & 568 & 189 & 187 \\
\hline Pseudo- $R^{2}$ & 0.52 & 0.31 & 0.023 & 0.035 \\
\hline log-likelihood & - & - & $-1,221.1$ & -684.0 \\
\hline \multirow{3}{*}{ Recipient $\times$ Post-Grant } & \multicolumn{4}{|c|}{ Panel B. Phase 2} \\
\hline & -0.139 & 0.039 & 0.079 & 0.600 \\
\hline & $(0.470)$ & $(0.042)$ & $(0.515)$ & $(0.695)$ \\
\hline Obs. & 1,389 & 1,389 & 458 & 471 \\
\hline Clusters (firms) & 152 & 152 & 54 & 51 \\
\hline Pseudo- $R^{2}$ & 0.61 & 0.51 & 0.027 & 0.085 \\
\hline log-likelihood & - & - & -774.6 & -195.1 \\
\hline Firm FEs & Yes & Yes & Yes & Yes \\
\hline Time FEs & Yes & Yes & Yes & Yes \\
\hline
\end{tabular}

Notes: Standard errors are clustered at the firm level for OLS and Poisson estimators and bootstrapped at the firm level with 200 replications for logit estimator. ** $p<0.05, * p<0.1$

specification. The point estimates show a declining trend before the R\&D grant assignment, which suggests a pre-trend and casts doubt on the validity of our identification strategy for this specification. ${ }^{18}$ We also perform a more formal test for the null hypothesis that the estimated coefficients for each lead in the pre-intervention period are equal to one another $\left(\beta_{-5}=\ldots=\beta_{-1}\right)$. In all cases, the $F$-test is not statistically significant with the $p$-value that exceeds the 10 percent level, which confirms our empirical framework.

\section{The Effects of R\&D Grants on Innovation Performance}

\subsection{Effects of the SME Instrument Program}

Table 3 reports the main results from specification (2). Panel A presents the results for the effect of public subsidies for Phase 1 program winners. Column (1) reports the estimated coefficients for the natural logarithm of the number of patent applications (i.e., the intensive margin) as an outcome variable by using OLS specification. The point estimate is positive, but it is only significant at the 10 percent level. The additional number of patent applications could come from recipient firms that would not have filed a patent without the grant (i.e., the extensive margin). Column (2) presents the OLS estimate for the extensive margin. The coefficient is positive and significant, which suggests that the effect of the SMEI program leads to a 4.6 percentage points increase in the extensive margin, relative to a mean of percent 0.1. Column (3) replicates the results in column (1) using PQML specification. The point estimate is positive and statistically significant at the 5 percent level, which suggests that $R \& D$ grants increase the intensive margin response of the number of patent applications by 1.7 times relative to non-recipient firms. The remaining column shows the extensive margin response on whether program winners have a higher probability of patenting, relative to non-recipient firms, by using a logit estimator. The point

\footnotetext{
${ }^{18}$ In unreported robustness tests, we replicated this specification with a Negative Binomial estimator, suggesting no changes in the recipient firms' number of patent applications, relative to non-recipient firms.
} 
estimate indicates that $R \& D$ grants enhance the likelihood of patenting. The marginal effect of treatment on the chance of patenting is roughly 0.24 , meaning that the likelihood of filing for a patent increases by around 24 percentage points on average. ${ }^{19}$ Our results emphasize that $R \& D$ grants of $€ 50,000$ increase firms' patenting activity at both the intensive and extensive margins (Santoleri et al., 2020). However, the baseline results are quite similar in terms of magnitude, which suggests that the primary effect of the $R \& D$ grants must be on the extensive margin response, and increases the number of firms that applied for at least one international patent after receiving a European subsidy.

Panel B reports the results for the Phase 2 winners, which obtain average grants equal to $€ 1,251,004$. In all specifications, the point estimates are not statistically significant at conventional levels. These differences with the estimates for Phase 1 in Panel A imply that the effect on Phase 2 winners does not imply an additionality effect on the patenting activities of recipient firms in the short-run. A potential explanation for the absence of positive effects on firms' patenting activity, on both the intensive and extensive margins, might be that SMEs undertake radically new technology investments with a longer exploration and development time. While we cannot reject the possibility that the policy has some impact, the insignificant estimates are informative for two reasons. First, estimated magnitudes are economically small, in contrast to previous findings that report large positive effects of R\&D grants. Abadie (2020) suggests that insignificant results are more informative than significant results when there is a prior on finding a significant effect and sufficient power. For example, Howell (2017) finds that the SBIR DOE program, on which the SMEI is designed, increased patent citations by 22 to 32 percent for firms that participate in Phase 2. Santoleri et al. (2020) document that Phase 2 of the SMEI program have sizable positive effects on innovation, increasing patent citations by 15 to 31 percent over the 2014-2019 period. Second, we implement a method to calculate power in a difference-in-difference framework i.e., the probability of rejecting the null across all outcomes when the policy impacted at least one of the outcomes, following Burlig et al. (2020). We find sufficiently high power (more than 0.5 ).$^{20}$ Therefore, the null results provide useful new information on R\&D grant programs given the view of policymakers that these programs can be effective in increasing innovation.

This positive effect for proof-of-concept grants is a key result. This phase reaches the feasibility of the innovative idea. However, the program does not require applicants to engage in patenting activities by the application deadline, nor does it require the lump sum to result in patent applications. Even though innovation is the goal of programs that subsidize $R \& D$ investments, there is no administrative pressure to file a patent as a result of the European grant, suggesting the effectiveness of this program to translate experimentation and investments into innovation.

\subsection{Magnitudes of the SMEI Program}

An interesting perspective on evaluating the effectiveness of a grant program is to consider the overall magnitude in terms of additional patents and the cost per patent attributable to the SMEI program. We apply the PQML coefficients in Panel A of Tables 3 and 4 to the number of Phase 1 recipient firms to calculate an estimate of the overall difference in the number of patent applications between the recipient

\footnotetext{
${ }^{19}$ These results on the intensive and extensive margin response with respect to policy intervention as well as estimated magnitudes are in line with the literature on R\&D subsidies public support. On northern Italian program, Bronzini and Piselli (2016) report that program winners increase on average by 1 the number of patents and 12 percent the probability of patenting on the post-intervention period. Concerning the SBIR program, Howell (2017) finds that Phase 1 winners increase cite-weighted patents (in log transformation) by 30 percent and by 9 percentage points the probability of patenting.

${ }^{20} \mathrm{We}$ calculate the power for each outcome variable by assuming an effect of 3 percent (small) or 5 percent (medium), and a significance level of 10 percent. The test suggests a power of $0.59(0.89)$ for the intensive margin, and $0.89(0.99)$ for the extensive margin).
} 
and non-recipient firms. Multiplying the estimated coefficients $(0.555,0.492$, and 0.529$)$ by the number of treated firms suggests that the R\&D grants generated 105 to 111 additional patent applications for a total of 282 patent applications reported at the end of our analysis period. For Phase 1 winners, the total R\&D grant awarded by the SMEI program was 9,45 million euros in 2014 in the form of a lump sum of $€ 50,000$. Using this information, together with the number of patent applications generated by the recipient firms, we can calculate the direct cost per patent due to the program. Thus, the direct cost per patent generated among the program's laureates ranges from $€ 90,090$ to $€ 101,626$.

Note that we cannot perform a complete cost-benefit analysis of the R\&D subsidies for at least two reasons. First, we are unable to account for the administrative cost involved in the policy intervention, such as application and management costs. Second, it is difficult to account for national public support, tax distortions across European countries, tax incentives and knowledge spillovers into competitors and sectors that could positively (or negatively) impact patent applications. In addition, general equilibrium effects such as the increase in scientist wages are impossible to scale with our counterfactual framework. Nevertheless, our estimates permit us to give an overview of the effectiveness of the program. Our costper-patent is lower than previous findings in Italy (Bronzini and Piselli, 2016). ${ }^{21}$ These differences can be explained in part by policy design and the regional context. The SMEI program is different from the Italian place-based program evaluated in Bronzini and Piselli (2016). First, the Italian policy provides a higher number of subsidies that cover project costs of between $€ 150,000$ and $€ 250,000$, which is three and five times more than the Phase 1 grant in the SMEI program, respectively. Finally, the program is located in northern Italy. SMEs in Emilia-Romagna differ from the overall population of Italian and European SMEs in that they plan for highly innovative investments. They represent a small number of firms within the region.

A full welfare analysis should account for distortions, but these figures suggest that the R\&D grants for proof of concept may be relatively costly as innovation incentives. However, three explanations may mitigate this negative assessment of the SMEI program. Patent applications are highly reliable to indicate innovation quality and the economic value of knowledge (Griliches, 1990; Kogan et al., 2017), but all inventions are not radical, and economic values are highly skewed. Another explanation is that recipient firms undertake additional $R \& D$ investments (which is beyond the scope of this paper) with long development cycles until the patentability of their inventions, which reduces the figures within the post-intervention period. Moreover, we only rely on the estimated direct cost-per-patent, but the social value can be larger.

\subsection{Robustness Tests}

Matching Procedure - Our baseline results rely on nearest-neighbor matching without replacement to construct counterfactual groups. We test whether our matching procedure plays a crucial role for our results. First by using weight observations from the inverse propensity score of the R\&D grant assignment. Inverse propensity score weighting (IPW) has an advantage compared to other matching procedures because it uses all observations in the potential control group and creates a pseudo population in which the treatment is statistically independent of the outcome, conditional on observable characteristics $\mathrm{X}_{i}$ (Abadie and Cattaneo, 2018). We chose this alternative estimator as suggested by Busso et al. (2014) that show he tends to perform well in finite samples. Second, we perform an alternative nearest-neighbor matching without replacement using the Mahalanobis distance rather than conditioning on the propen-

\footnotetext{
${ }^{21}$ Surprisingly, evidence on cost-per-patent in the context of R\&D subsidies is scarce. In contrast, several previous studies provide back of envelope calculation on cost per job and R\&D investments (Czarnitzki and Lopes-Bento, 2013; Boeing, 2016).
} 
sity score (Imbens, 2003). Finally, we use new methods of program evaluation using machines from the high-dimensional literature in statistics, named the post-double selection method (Belloni et al., 2014). This statistical procedure allows us to increase and select the appropriate covariates to satisfy the CIA. Specifically, the least absolute shrinkage and selection operator (LASSO) is performed then we rely on the nearest-neighbor matching from the parsimonious set of selected covariates. ${ }^{22}$ Table 4 presents the results for alternative matching procedures. The results are robust to this alternative matching procedure. Only the point estimates for the number of patent applications turn insignificant when using Mahalanobis matching with a smaller absolute value of coefficient. Taken together, our results are robust with respect to the matching procedure applied.

Table 4. Alternative Matching

\begin{tabular}{|c|c|c|c|c|}
\hline \multirow[b]{2}{*}{ Dependent variable: } & \multicolumn{2}{|c|}{ Phase 1 } & \multicolumn{2}{|c|}{ Phase 2} \\
\hline & (1) Patent & (2) Appl & (3) Patent & (4) Appl \\
\hline \multirow{3}{*}{ Recipient $\times$ Post-Grant } & \multicolumn{4}{|c|}{ Panel A. IPW } \\
\hline & $0.492 * *$ & $0.447 * *$ & $0.343^{*}$ & 0.873 \\
\hline & $(0.231)$ & $(0.210)$ & $(0.176)$ & $(0.845)$ \\
\hline \multirow{3}{*}{ Recipient $\times$ Post-Grant } & \multicolumn{4}{|c|}{ Panel B. Mahalanobis } \\
\hline & 0.439 & $0.887 * *$ & -0.106 & 0.858 \\
\hline & $(0.282)$ & $(0.361)$ & $(0.443)$ & $(0.847)$ \\
\hline \multirow{3}{*}{ Recipient $\times$ Post-Grant } & \multicolumn{4}{|c|}{ Panel C. NN-LASSO } \\
\hline & $0.519^{*}$ & $0.670^{* *}$ & -0.176 & 0.628 \\
\hline & $(0.301)$ & $(0.327)$ & $(0.479)$ & $(0.749)$ \\
\hline Firm FEs & Yes & Yes & Yes & Yes \\
\hline Time FEs & Yes & Yes & Yes & Yes \\
\hline
\end{tabular}

Notes: Standard errors are clustered at the firm level for OLS and Poisson estimators and bootstrapped at the firm level with 200 replications for logit estimator. $* p<0.1, * * p<0.05, * * * p<0.01$

Sensitivity to Unobservables - One concern is that there are unobservable characteristics whose effect may not be mitigated by the identification strategy. The validity of the empirical strategy that combines matching and DID is based on the unconfoundedness assumption assuming that potential outcomes are independent of the treatment after conditioning on observable characteristics. This assumption can be violated if an exogenous shock affects both the likelihood to apply to the European program and the innovation performances at the firm-level. For example, firms might apply because they are well-informed about the program or due to investment opportunities. To access coefficient sensitivity, we use the insight from Oster (2019). ${ }^{23}$ The idea of the test is to compare the degree of coefficient movements with the amount of movement in R-squared value for specification with no control and another with a sparse set of observable characteristics. We consider two sets of sparse covariates: one with a sparse set of firm-level controls that includes two-way interactions between year and industry indicators and age, and another

\footnotetext{
${ }^{22}$ We build upon the recent literature of program evaluations to select higher-dimensional observable baseline characteristics. We include in the LASSO the following baseline characteristics: country location, industry location, firm age, size, stock of intangible and tangible assets, the stock of patents, high-tech manufacturing, and knowledge-intensive services (KIS) indicators, and interaction terms(on the one hand between the patent stock and firm age, size, high-tech, and KIS, and on the other hand between high-tech and KIS indicators with firm age and size).

${ }^{23} \mathrm{We}$ also test the sensitivity of our results to unobservables that affect assignment to treatment and innovation performance with an alternative approach, the bounding approach developed by Rosenbaum (2002). In contrast to the Oster (2019) test, this approach applies directly to ATET estimates from matching estimators. The bounding approach allows us to establish whether our estimated treatment effects would still be significantly different from zero for a value of the degree of departure from a study that is free of hidden bias (Rosenbaum, 2002). Our results are robust for this alternative sensitivity test.
} 
that includes age, age squared, lagged patent stock, and the two-way interaction between year and industry indicators. Then we calculate delta ratios, which represent the ratio of selection on unobservables relative to selection on observables that would be necessary to explain the result (Oster, 2019). ${ }^{24}$ Appendix Table A.5 reports the delta ratios. Reassuringly, all ratios obtained are greater than one or less than zero, suggesting that the selection on the unobservable should be several times greater than the selection on the observable to explain the full effect of the treatment.

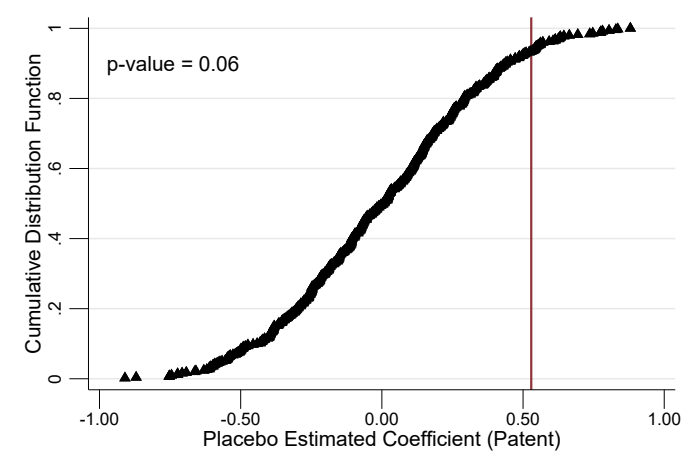

(A) Phase 1: Patent

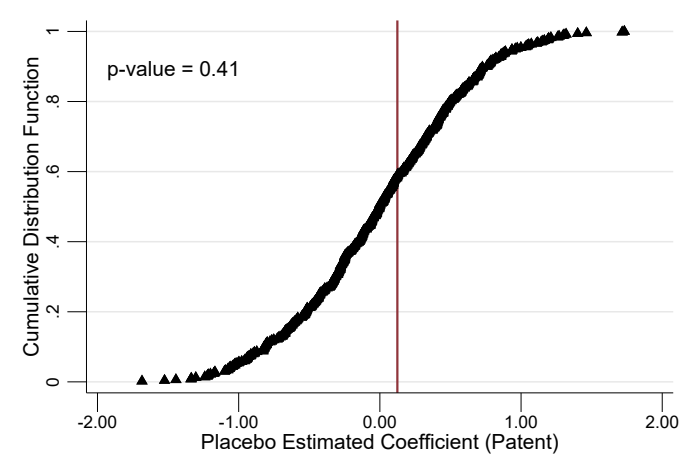

(C) Phase 2: Patent

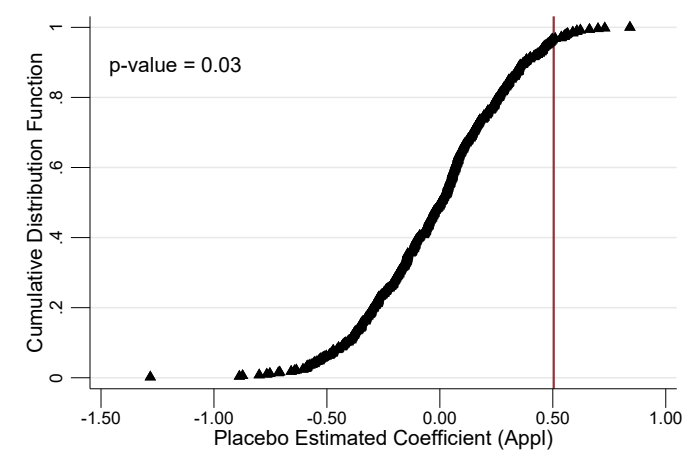

(B) Phase 1: Appl

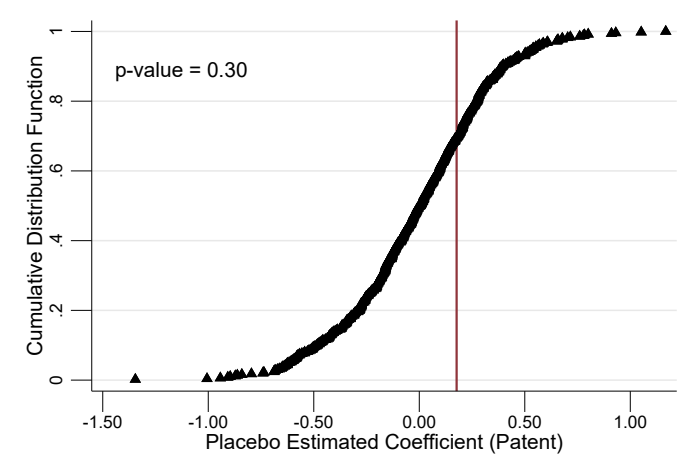

(D) Phase 2: Appl

Figure 4. Permutation Tests

Notes: This figure shows the empirical cumulative density function (CDF) from placebo estimates for our main outcome variables. Figure (A-B) plot the empirical distribution for Phase 1, and Figure (C-D) for Phase 2. The four CDFs are constructed from 500 estimates of our main coefficient of interest by randomly chosen placebo recipient firms at each replication. The vertical line stands the estimated causal effect reported in baseline results (Table 4).

Permutation Tests- An important concern with our identification strategy is that standard errors may be biased by serial correlation and on rejecting the null hypothesis of no causal effect $\beta_{1}=0$ (Bertrand et al., 2004; Ohrn, 2018; Chetty et al., 2009). To address this concern and provide a placebo test, we implement a non-parametric permutation test that randomly draws 500 placebo samples. Specifically, with replacement, the treatment status is randomly assigned to firms in order to maintain the same number of treated and control observations as the baseline sample. We then reproduce specifications (4) and (5) in Table 3 for intensive and extensive margin responses using the placebo treatment as the true treat-

\footnotetext{
${ }^{24}$ As suggest by Oster (2019), we assume a maximum R-squared equal to 1.3 times the R-squared with a full set of controls. The test is performed on the OLS specification.
} 
ment and repeat this procedure 499 times. The permutation test is performed using the PQML and logit specifications. Figure 4 shows the empirical cumulative distribution function (CDF) from the 500-point estimates of the placebo treatment on our results. The vertical line represents the true treatment effect reported in our baseline results that re-estimates specification (5), and we find an estimated coefficient similar to baseline estimates. The point estimate is not significantly different from zero.

Panel A of Figure 4 shows the permutation test for the intensive margin variable in Phase 1 and the empirical CDF. Placebo effects are centered on zero with 30 point estimates that are greater than the actual treatment effect resulting in a nonparametric $p$-value of 0.06 . In Panel $\mathrm{B}$, the 15 point estimates are higher, suggesting a $p$-value of 0.03 . These results suggest that the positive and significant effect of the SMEI Phase 1 program on innovation performance is not driven by serial correlation and unobserved time-invariant characteristics. In contrast, for Phase 2, the permutation test yields a nonparametric p-value of 0.41 and 0.30 for the intensive (Panel C) and extensive (Panel D) margin responses, respectively. These nonparametric tests suggest that the effect of the R\&D subsidy on the number of patent applications and the probability of patenting is statistically insignificant, confirming our main results.

\subsection{Heterogeneous Responses to Firm Characteristics}

In this section, we further examine how the effect of R\&D grants may differ from firm characteristics. The discussion in Section 2 implied that the treatment effects could be heterogeneous and more pronounced for financially constrained firms (i.e., facing a higher cost of capital), with important policy implications for the program as well as for subsequent European Framework Programs (e.g. Horizon Europe from 2021). To explore the extent to which innovation performance responds to observable characteristics, we interacted a heterogeneity indicator with our key policy variable. As ex-ante financial constraints, we consider firm age and firm size. These two indicators are usually used as criteria to distinguish between constraint and unconstraint firms (Zwick and Mahon, 2017; Criscuolo et al., 2019). Firm age and size are split along the median, based on the pre-intervention period (2008-2013), and we define a heterogeneity indicator to be equal to one if the age (size) of firm $i$ is under the median and zero otherwise. The policy variable interacts with these indicators that allow estimating the heterogeneous causal effects and provide a simple test of the financing constraints hypothesis.

Table 5. Heterogeneous Responses to Firm Ex-ante Financial Constraints

\begin{tabular}{|c|c|c|c|c|}
\hline \multirow[b]{2}{*}{ Dependent variable: } & \multicolumn{2}{|c|}{ OLS } & \multirow{2}{*}{$\begin{array}{c}\text { Poisson } \\
\text { (3) Patent }\end{array}$} & \multirow{2}{*}{$\begin{array}{c}\text { logit } \\
\text { (4) Appl }\end{array}$} \\
\hline & (1) Patent & (2) Appl & & \\
\hline \multicolumn{5}{|l|}{ Recipient $\times$ Post-Grant } \\
\hline$\times$ Age & $\begin{array}{c}0.121 * * \\
(0.058)\end{array}$ & $\begin{array}{c}0.072 * * \\
(0.030)\end{array}$ & $\begin{array}{c}0.887 * * * \\
(0.297)\end{array}$ & $\begin{array}{c}0.874 * * \\
(0.413)\end{array}$ \\
\hline$\times$ Size & $\begin{array}{l}-0.042 \\
(0.047)\end{array}$ & $\begin{array}{l}-0.021 \\
(0.027)\end{array}$ & $\begin{array}{l}-0.068 \\
(0.299)\end{array}$ & $\begin{array}{l}-0.467 \\
(0.388)\end{array}$ \\
\hline
\end{tabular}

Notes: Standard errors are clustered at the firm level for OLS and Poisson estimators and bootstrapped at the firm level with 200 replications for logit estimator. ** $p<0.05, * * * p<0.01$

The interaction term between the policy variable and being young (less than eight years) is always positive and significant. The heterogeneity responses suggest that there is a larger program effect for young firms than for older firms. In contrast, the second line indicates that smaller firms are not more responsive on both the intensive and extensive margins. ${ }^{25}$ Interestingly, these findings contrast with

\footnotetext{
${ }^{25}$ This finding is robust to the measure of being small, using firm employment as a measure of size rather than total assets.
} 
recent empirical findings that find a stronger response to grants for smaller firms (Bronzini and Piselli, 2016; Criscuolo et al., 2019; Lach, 2002). This implies that firms that are part of small firms did not drove the average effect identified in the previous section. One possible explanation is that young firms might be more financially constrained because of asymmetric information with less time to credit markets to observe their performance, and they have fewer internal funds or capital to pledge as collateral. Since young firms respond more to the European program, the larger effect seems consistent with the financial constraint hypothesis (Howell, 2017). Hence, this result is consistent with previous studies (e.g., Brown et al. 2009; Farre-Mensa and Ljungqvist 2016) and recent evidence that stressed that young firms are more innovative than smaller firms (Haltiwanger et al., 2013).

\subsection{R\&D Grant Effects on Firm Performance}

We examine whether the European program has additional effects on firms' performance in the short term. The availability of firm-level balance sheets allows us to examine R\&D grants from several aspects other than innovation. We report regression on revenue, employment, and capital as the outcome variable using the baseline specification. In column 1 of Table 6, we find no significant effects on revenue using the Phase 1 and 2 samples. In column 4, we examine if more innovation performance translates into an increase in capital investment. Similar to revenue growth, there were also no significant program effects. Finally, in column 7, estimates are less precise and exhibit a similar pattern for Phase 1, but sizable and robust estimates of the policy for the Phase 2 subsample, suggesting that larger R\&D grants allow firms to grow larger. Given that these SMEs have received higher subsidies, may start ambitious creative initiatives, and boost $R \& D$, which takes a long time to achieve innovation output, the insignificant impacts on innovation performance with a favorable policy impact on employment seem reasonable.

Table 6. The Effect of Phase 1 and 2 on Firms Performance

\begin{tabular}{|c|c|c|c|c|c|c|c|c|c|}
\hline \multirow[t]{2}{*}{$\overline{\text { Dependent variable: }}$} & \multicolumn{3}{|c|}{ Revenue } & \multicolumn{3}{|c|}{ Capital Investment } & \multicolumn{3}{|c|}{ Employment } \\
\hline & (1) & (2) & (3) & (4) & (5) & (6) & (7) & (8) & (9) \\
\hline & \multicolumn{9}{|c|}{ Panel A. Phase 1} \\
\hline Recipient $\times$ Post-Grant & $\begin{array}{c}0.178 \\
(0.157)\end{array}$ & $\begin{array}{c}-0.037 \\
(0.158)\end{array}$ & $\begin{array}{c}0.062 \\
(0.156)\end{array}$ & $\begin{array}{c}0.184 \\
(0.113)\end{array}$ & $\begin{array}{c}0.052 \\
(0.121)\end{array}$ & $\begin{array}{c}0.108 \\
(0.108)\end{array}$ & $\begin{array}{c}0.029 \\
(0.067)\end{array}$ & $\begin{array}{l}-0.013 \\
(0.065)\end{array}$ & $\begin{array}{c}0.017 \\
(0.066)\end{array}$ \\
\hline$\times$ Age & & $\begin{array}{c}0.761 * * * \\
(0.186)\end{array}$ & & & $\begin{array}{c}0.472 * * * \\
(0.157)\end{array}$ & & & $\begin{array}{c}0.197 * * \\
(0.095)\end{array}$ & \\
\hline$\times$ Size & & & $\begin{array}{l}0.249^{*} \\
(0.132)\end{array}$ & & & $\begin{array}{c}0.058 \\
(0.135)\end{array}$ & & & $\begin{array}{c}0.025 \\
(0.083)\end{array}$ \\
\hline Obs. & 2,648 & 2,648 & 2,648 & 4,095 & 4,095 & 4,095 & 2,253 & 2,253 & 2,253 \\
\hline \multirow[t]{2}{*}{ Clusters (firms) } & 396 & 396 & 396 & 568 & 568 & 568 & 395 & 395 & 395 \\
\hline & \multicolumn{9}{|c|}{ Panel B. Phase 2} \\
\hline Recipient $\times$ Post-Grant & $\begin{array}{l}-0.027 \\
(0.410)\end{array}$ & $\begin{array}{l}-0.018 \\
(0.392)\end{array}$ & $\begin{array}{c}0.111 \\
(0.348)\end{array}$ & $\begin{array}{c}0.712^{* * * *} \\
(0.246)\end{array}$ & $\begin{array}{c}0.366 \\
(0.258)\end{array}$ & $\begin{array}{c}0.505^{* *} \\
(0.231)\end{array}$ & $\begin{array}{c}0.150 \\
(0.120)\end{array}$ & $\begin{array}{c}0.038 \\
(0.121)\end{array}$ & $\begin{array}{c}0.105 \\
(0.118)\end{array}$ \\
\hline$\times$ Age & & $\begin{array}{c}0.061 \\
(0.721)\end{array}$ & & & $\begin{array}{c}1.065 * * * \\
(0.307)\end{array}$ & & & $\begin{array}{c}0.368 * * * \\
(0.130)\end{array}$ & \\
\hline$\times$ Size & & & $\begin{array}{l}-0.749 \\
(0.666)\end{array}$ & & & $\begin{array}{c}0.423 \\
(0.340)\end{array}$ & & & $\begin{array}{c}0.052 \\
(0.138)\end{array}$ \\
\hline Obs. & 419 & 419 & 419 & 1,141 & 1,141 & 1,141 & 597 & 597 & 597 \\
\hline Clusters (firms) & 90 & 90 & 90 & 152 & 152 & 152 & 128 & 128 & 128 \\
\hline Firm FEs & Yes & Yes & Yes & Yes & Yes & Yes & Yes & Yes & Yes \\
\hline Time FEs & Yes & Yes & Yes & Yes & Yes & Yes & Yes & Yes & Yes \\
\hline
\end{tabular}

Notes: Standard errors are clustered at the firm level. ${ }^{*} p<0.1,{ }^{* *} p<0.05,{ }^{* * *} p<0.01$

Motivated by the heterogeneous responses in Section 5.4, suggesting that young firms are more responsive to the policy, we interacted our key policy variable with a heterogeneity indicator. Table 
5 reports sizable estimates of the R\&D grants on revenue for young firms that participate in Phase 1 . We also find smaller impacts on employment than for the capital for young firms, consistent with the theoretical model in Section 2. These results suggest that young firms innovate by increasing capital investment and then grow and improve their revenues.

Overall, these results should be interpreted with caution. As discussed above, there are many missing values on balance-sheet variables of revenue and employment as accounting regulations do not insist on these being reported for SMEs in European countries. Nevertheless, the results suggest that the policy positively impacts other measures of firm performance as well as innovation output.

\section{Potential Mechanisms: The Effect on External Capital}

What are the mechanisms that explain the R\&D grant effect in Phase 1 on innovation performance? $R \& D$ grants could improve patenting activities through two main mechanisms. The first direct mechanism might improve the innovation performance of SMEs through its positive impact on internal funds accumulation due to the subsidy amount. By contrast, R\&D grants can directly reduce the user cost of capital toward financially constrained firms. We, therefore, explore more broadly the role of credit constraints in this section. ${ }^{26}$

To determine whether $R \& D$ grants affect the use of debt finance and ease the financing constraints of SMEs, we re-estimate the specification (2), where outstanding debt is our outcome of interest, differentiating between short- and long-term maturities. ${ }^{27}$ Table 7 reports the subsequent financing regressions. Columns (1) and (4) demonstrate that recipient firms use more short-term debt than non-recipient firms, while their capacity to attract long-term financing remains unchanged. These results show that government support alleviates the financing constraints of the Phase 1 recipients on the use of shorter-term (less than one year) liabilities. To confirm that SMEs face greater R\&D investment financing constraints hypothesis, the remaining columns test whether young and small firms respond more than their peers by interacting the treatment effects with ex-ante financial constraint indicators. As expected, the results show a heterogeneous response to the $R \& D$ grant. The point estimates of short- and long-term debt are positive and statistically significant for young firms. This effect on the stock of debt appears larger for short-term than for long-term debt (2.1 versus 1.6). Similarly, the point estimate in column (6) is statistically significant for small firms (i.e., 1.3). However, it is no different from zero for small firms in the use of short-term debt. Consistent with the model, we show that program winners attract more financing from credit markets after receiving R\&D grants, suggesting that the SMEI program has a greater impact on firms that are more likely to be financially constrained.

Our findings on the greater impact of young and small firms benefiting from a European subsidy on the stock of short- and long-term debt can be derived from two mechanisms, a resource or a signal effect (Lerner, 2000; Howell, 2017). First, the resource effect could ease financing constraints through the amount of the grant, allowing firms to test ideas and invest in R\&D for prototyping, strengthen the balance sheet and thus reduce project uncertainty (Howell, 2017). On the other hand, R\&D grants could have a signaling effect on external investors regarding the quality of projects, reduce informational asymmetries, indicate early success, and reduce the cost of using external capital. ${ }^{28}$ To discriminate

\footnotetext{
${ }^{26}$ Note that we do not attempt to examine the exact mechanisms of the R\&D grant effect, but shed more light on the market failures such as imperfect capital markets.

${ }^{27}$ Our measures of loan outstanding are transformed in the following form $\ln (1+\mathrm{x})$, given the existence of zero values reported in the balance sheet.

${ }^{28}$ Note that the signal or certification effect requires competition among applicants and the signal must be observable to investors, especially for selective subsidies, instead of automatic public support (Colombo et al., 2011).
} 
Table 7. Effect on External Capital

\begin{tabular}{|c|c|c|c|c|c|c|}
\hline \multirow{2}{*}{ Dependent variable: } & \multicolumn{3}{|c|}{ Short-term Debt } & \multicolumn{3}{|c|}{ Long-term Debt } \\
\hline & (1) & (2) & (3) & (4) & (5) & (6) \\
\hline \multicolumn{7}{|c|}{ Panel A. Without Controls } \\
\hline \multirow[t]{2}{*}{ Recipient $\times$ Post-Grant } & $0.692^{*}$ & -0.006 & 0.386 & 0.557 & 0.073 & 0.086 \\
\hline & $(0.410)$ & $(0.489)$ & $(0.503)$ & $(0.421)$ & $(0.451)$ & $(0.446)$ \\
\hline \multirow{2}{*}{$\times$ Age } & & $2.163 * * *$ & & & $1.626 * * *$ & \\
\hline & & $(0.647)$ & & & $(0.628)$ & \\
\hline \multirow[t]{3}{*}{$\times$ Size } & & & 0.654 & & & $1.315^{* * *}$ \\
\hline & & & $(0.556)$ & & & $(0.500)$ \\
\hline & Pan & B. Contro & ng of the & unt of th & Grant & \\
\hline \multirow[t]{2}{*}{ Recipient $\times$ Post-Grant } & $0.689^{*}$ & -0.005 & 0.388 & 0.558 & 0.073 & 0.081 \\
\hline & $(0.410)$ & $(0.457)$ & $(0.470)$ & $(0.391)$ & $(0.418)$ & $(0.414)$ \\
\hline \multirow[t]{2}{*}{$\times$ Age } & & $2.154 * * *$ & & & $1.633 * * *$ & \\
\hline & & $(0.650)$ & & & $(0.584)$ & \\
\hline \multirow[t]{2}{*}{$\times$ Size } & & & 0.644 & & & $1.336 * * *$ \\
\hline & & & $(0.556)$ & & & $(0.466)$ \\
\hline \multirow[t]{2}{*}{ Grant Size } & -0.370 & -0.249 & -0.177 & 0.109 & 0.185 & 0.330 \\
\hline & $(0.250)$ & $(0.239)$ & $(0.208)$ & $(0.241)$ & $(0.228)$ & $(0.207)$ \\
\hline Firm FEs & Yes & Yes & Yes & Yes & Yes & Yes \\
\hline Time FEs & Yes & Yes & Yes & Yes & Yes & Yes \\
\hline Obs. & 3,726 & 3,726 & 3,726 & 3,490 & 3,490 & 3,490 \\
\hline Clusters (firms) & 474 & 474 & 474 & 481 & 481 & 481 \\
\hline
\end{tabular}

Notes: Standard errors are clustered at the firm level. $* p<0.1, * * * p<0.01$

between these two mechanisms, we control for the size of the grant amount relative to total assets (e.g., Meuleman and De Maeseneire 2012. If the main mechanism is a resource effect that allows SMEs to develop ideas and thus reduce investment risk, a larger subsidy should have a higher effect than on firms that receive smaller subsidies (Lerner, 2000; Howell, 2017). ${ }^{29}$ Panel B of Table 7 reports the subsequent financing regressions where we control for the relative size of the subsidy. Regardless of the size of the $R \& D$ grants, the point estimates confirm a significant and positive increase in the response of young and small firms to subsequent debt financing. Hence, the point estimates associated with a lump sum of $€ 50,000$ relative to total assets are statistically insignificant, reinforcing that the signaling channel is the main mechanism that drives our results.

Taken together, our findings do not support the view that the resource effect is the primary mechanism by which R\&D grants reduce financial constraints for Phase 1 recipients. Instead, we find evidence that obtaining proof-of-concept grants could convey information about the quality of the project to external investors. Regardless of the size of the grant, selection into the program is informative and produces a signal effect for young and small firms. Through the signal effect, the R\&D grant reduces informational frictions and lowers the user cost of capital, as suggested by the theory in Section 2. This result is consistent with previous evidence in the European context (e.g., Meuleman and De Maeseneire 2012). However, the signal effect contrasts with the evidence from Howell 2017 which finds that obtaining an SBIR grant alleviates financing constraints and allows firms to develop prototyping, thus reducing uncertainty about the quality of the firm.

\footnotetext{
${ }^{29}$ The amount of the R\&D grant awarded in Phase 1 is the same for all program winners. As a result, the program's design prevents us from using variation in the specification of fixed effects.
} 


\section{Conclusion}

Industrial policies and R\&D public supports are increasingly implemented across OECD and emerging countries to support private innovation research. Surprisingly, there is limited evidence on the effectiveness of direct grants on innovation outcomes. In this paper, we have examined one European R\&D subsidy program, the SMEI program, which is modeled after the US SBIR program. By using a newly assembled dataset on the universe of program winners and randomly drawn innovative European SMEs, we randomize the public support conditional on observable characteristics. Then, we examine the effect of R\&D grants on innovation outputs and firm performance. Our findings suggest that the SMEI program has a substantial effect on the firms' patent applications and the probability of patenting in the phase of proof of concept, whereas the effect is indistinguishable from zero in the phase of commercialization development. Interestingly, the lack of impact of later stages of development is compensated for by a positive effect on investment and employment. These findings imply that public support is effective at spurring additional investment. We also show that young and large firms are substantially more responsive to R\&D grants. This evidence is partially consistent with the financial frictions that more severely affect early-stage ventures and young SMEs. An examination of the underlying mechanisms suggests that $R \& D$ grants in the proof of concept phase have been used to raise a young firm's use of external capital, with a strong signal effect on external investors, reducing uncertainty about project quality. Therefore, our results suggest that $R \& D$ grants are effective in stimulating innovative experimentation through realizing innovation output and securing the financial position of young firms. Finally, our findings in the proof of concept phase suggest that the direct cost-per-patent ranges between $€ 90,090$ and $€ 101,626$, which suggests a relatively expensive cost relative to the lump sum awarded.

From a policy perspective, the fact that this European public support was effective in improving innovation outcomes for young innovative firms strengthens arguments for allocating more early-stage grants, although care must be taken in order to address societal challenges. 


\section{References}

Abadie, A. (2020). Statistical Nonsignificance in Empirical Economics. American Economic Review: Insights, 2(2):193-208.

Abadie, A. and Cattaneo, M. D. (2018). Econometric Methods for Program Evaluation. Annual Review of Economics, 10:465-503.

Arrow, K. (1962). Economic Welfare and the Allocation of Resources for Invention. Technical report, National Bureau of Economic Research, Inc.

Autor, D., Dorn, D., Katz, L. F., Patterson, C., and Van Reenen, J. (2020). The Fall of the Labor Share and the Rise of Superstar Firms. The Quarterly Journal of Economics, 135(2):645-709.

Belloni, A., Chernozhukov, V., and Hansen, C. (2014). Inference on Treatment Effects After Selection Among High-dimensional Controls. The Review of Economic Studies, 81(2):608-650.

Bertrand, M., Duflo, E., and Mullainathan, S. (2004). How Much Should We Trust Differences-indifferences Estimates? The Quarterly Journal of Economics, 119(1):249-275.

Bloom, N., Van Reenen, J., and Williams, H. (2019). A Toolkit of Policies to Promote Innovation. Journal of Economic Perspectives, 33(3):163-84.

Blundell, R. and Costa Dias, M. (2000). Evaluation methods for non-experimental data. Fiscal studies, 21(4):427-468.

Boeing, P. (2016). The allocation and effectiveness of China's R\&D subsidies - Evidence from listed firms. Research Policy, 45(9):1774-1789.

Bronzini, R. and Iachini, E. (2014). Are Incentives for R\&D effective? Evidence from a Regression Discontinuity Approach. American Economic Journal: Economic Policy, 6(4):100-134.

Bronzini, R. and Piselli, P. (2016). The Impact of R\&D Subsidies on Firm Innovation. Research Policy, 45(2):442-457.

Brown, J. R., Fazzari, S. M., and Petersen, B. C. (2009). Financing Innovation and Growth: Cash Flow, External Equity, and the 1990s R\&D Boom. The Journal of Finance, 64(1):151-185.

Burlig, F., Preonas, L., and Woerman, M. (2020). Panel data and experimental design. Journal of Development Economics, 144:102458.

Busso, M., DiNardo, J., and McCrary, J. (2014). New Evidence on the Finite Sample Properties of Propensity Score Reweighting and Matching Estimators. Review of Economics and Statistics, 96(5):885-897.

Carpenter, R. E. and Petersen, B. C. (2002). Is the Growth of Small Firms Constrained by Internal Finance? Review of Economics and Statistics, 84(2):298-309.

Cerqua, A. and Pellegrini, G. (2014). Do Subsidies to Private Capital Boost Firms' Growth? A Multiple Regression Discontinuity Design Approach. Journal of Public Economics, 109:114-126.

Chetty, R., Looney, A., and Kroft, K. (2009). Salience and Taxation: Theory and Evidence. American economic review, 99(4):1145-77.

Cincera, M., Ravet, J., and Veugelers, R. (2016). The sensitivity of R\&D investments to cash flows: comparing young and old EU and US leading innovators. Economics of Innovation and New Technology, 25(3):304-320.

Colombo, M. G., Grilli, L., and Murtinu, S. (2011). R\&D subsidies and the performance of high-tech start-ups. Economics Letters, 112(1):97-99.

Criscuolo, C., Martin, R., Overman, H. G., and Van Reenen, J. (2019). Some Causal Effects of an Industrial Policy. American Economic Review, 109(1):48-85.

Czarnitzki, D. and Hottenrott, H. (2011). R\&D investment and financing constraints of small and 
medium-sized firms. Small Business Economics, 36(1):65-83.

Czarnitzki, D. and Lopes-Bento, C. (2013). Value for money? New microeconometric evidence on public R\&D grants in Flanders. Research Policy, 42(1):76-89.

Czarnitzki, D. and Lopes-Bento, C. (2014). Innovation Subsidies: Does the Funding Source Matter for Innovation Intensity and Performance? Empirical Evidence from Germany. Industry and Innovation, 21(5):380-409.

Dechezleprêtre, A., Einiö, E., Martin, R., Nguyen, K.-T., and Van Reenen, J. (2016). Do Tax Incentives for Research Increase Firm Innovation? An RD Design for R\&D. Technical report, National Bureau of Economic Research.

Dimos, C. and Pugh, G. (2016). The effectiveness of R\&D subsidies: A meta-regression analysis of the evaluation literature. Research Policy, 45(4):797-815.

Farre-Mensa, J. and Ljungqvist, A. (2016). Do Measures of Financial Constraints Measure Financial Constraints? The Review of Financial Studies, 29(2):271-308.

González, X., Jaumandreu, J., and Pazó, C. (2005). Barriers to innovation and subsidy effectiveness. RAND Journal of Economics, pages 930-950.

Görg, H., Henry, M., and Strobl, E. (2008). Grant support and exporting activity. The Review of Economics and Statistics, 90(1):168-174.

Gourieroux, C., Monfort, A., and Trognon, A. (1984). Pseudo maximum likelihood methods: Theory. Econometrica: Journal of the Econometric Society, pages 681-700.

Griliches, Z. (1990). Patent Statistics as Economic Indicators: A Survey. Journal of Economic Literature, 28(4):1661-1707.

Guceri, I. and Liu, L. (2019). Effectiveness of Fiscal Incentives for R\&D: Quasi-experimental Evidence. American Economic Journal: Economic Policy, 11(1):266-91.

Hall, B. H. and Lerner, J. (2010). The Financing of R\&D and Innovation. In Handbook of the Economics of Innovation, volume 1, pages 609-639. Elsevier.

Hall, B. H., Mairesse, J., and Mohnen, P. (2010). Measuring the Returns to R\&D. In Handbook of the Economics of Innovation, volume 2, pages 1033-1082. Elsevier.

Hall, B. H., Moncada-Paterno-Castello, P., Montresor, S., and Vezzani, A. (2016). Financing constraints, R\&D investments and innovative performances: new empirical evidence at the firm level for Europe. Economics of Innovation and New Technology, 25(3):183-196.

Haltiwanger, J., Jarmin, R. S., and Miranda, J. (2013). Who creates jobs? Small versus large versus young. Review of Economics and Statistics, 95(2):347-361.

Heckman, J., Ichimura, H., Smith, J., and Todd, P. (1998). Characterizing Selection Bias Using Experimental Data. Econometrica, 66(5):1017-1098.

Howell, S. T. (2017). Financing Innovation: Evidence from R\&D Grants. American Economic Review, 107(4):1136-64.

Hünermund, P. and Czarnitzki, D. (2019). Estimating the causal effect of R\&D subsidies in a panEuropean program. Research Policy, 48(1):115-124.

Hutschenreiter, G., Weber, J., and Rammer, C. (2019). Innovation Support in the Enterprise Sector: Industry and SMEs.

Imbens, G. W. (2003). Sensitivity to Exogeneity Assumptions in Program Evaluation. American Economic Review, 93(2):126-132.

Imbens, G. W. and Lemieux, T. (2008). Regression discontinuity designs: A guide to practice. Journal of Econometrics, 142(2):615-635.

Imbens, G. W. and Rubin, D. B. (2015). Causal Inference in Statistics, Social, and Biomedical Sciences. 
Cambridge University Press.

Kogan, L., Papanikolaou, D., Seru, A., and Stoffman, N. (2017). Technological Innovation, Resource Allocation, and Growth. The Quarterly Journal of Economics, 132(2):665-712.

Lach, S. (2002). Do R\&D Subsidies Stimulate or Displace Private R\&D? Evidence from Israel. The Journal of Industrial Economics, 50(4):369-390.

Le, T. and Jaffe, A. B. (2017). The Impact of R\&D Subsidy on Innovation: Evidence from New Zealand Firms. Economics of Innovation and New Technology, 26(5):429-452.

Lerner, J. (2000). The Government as Venture Capitalist: The Long-run Impact of the SBIR Program. The Journal of Private Equity, pages 55-78.

Meuleman, M. and De Maeseneire, W. (2012). Do R\&D subsidies affect SMEs' access to external financing? Research Policy, 41(3):580-591.

Mina, A., Di Minin, A., Martelli, I., Testa, G., and Santoleri, P. (2020). Public funding of innovation: Exploring applications and allocations of the European SME Instrument. Research Policy, 50(1):104131.

Nelson, R. R. (1959). The Simple Economics of Basic Scientific Research. Journal of Political Economy, 67(3):297-306.

Neumark, D. and Simpson, H. (2015). Place-based Policies. In Handbook of regional and urban economics, volume 5, pages 1197-1287. Elsevier.

Ohrn, E. (2018). The Effect of Corporate Taxation on Investment and Financial Policy: Evidence from the DPAD. American Economic Journal: Economic Policy, 10(2):272-301.

Oster, E. (2019). Unobservable Selection and Coefficient Stability: Theory and Evidence. Journal of Business \& Economic Statistics, 37(2):187-204.

Rao, N. (2016). Do tax credits stimulate R\&D spending? The effect of the R\&D tax credit in its first decade. Journal of Public Economics, 140:1 - 12.

Rosenbaum, P. R. (2002). Sensitivity to Hidden Bias. In Observational studies, pages 105-170. Springer.

Rubin, D. B. (1974). Estimating causal effects of treatments in randomized and nonrandomized studies. Journal of educational Psychology, 66(5):688.

Santoleri, P., Mina, A., Di Minin, A., and Martelli, I. (2020). The causal effects of R\&D grants: evidence from a regression discontinuity. Available at SSRN 3637867.

Spence, M. (1973). Job Market Signaling. The Quarterly Journal of Economics, 87(3):355-374.

Stiglitz, J. E. and Weiss, A. (1981). Credit Rationing in Markets with Imperfect Information. The American economic review, 71(3):393-410.

Wallsten, S. J. (2000). The effects of government-industry R\&D programs on private R\&D: the case of the Small Business Innovation Research program. The RAND Journal of Economics, pages 82-100.

Zúñiga-Vicente, J. Á., Alonso-Borrego, C., Forcadell, F. J., and Galán, J. I. (2014). Assessing the effect of public subsidies on firm R\&D investment: a survey. Journal of Economic Surveys, 28(1):36-67.

Zwick, E. and Mahon, J. (2017). Tax Policy and Heterogeneous Investment Behavior. American Economic Review, 107(1):217-48. 


\section{A Appendix}

Table A.1. SME Instrument Proposal Distribution

\begin{tabular}{lccc}
\hline \hline & Total SMEI & Phase 1 & Phase 2 \\
\cline { 2 - 4 } Panel A: Overall sample & & & \\
\hline Proposal evaluated & 8182 & 6973 & 1209 \\
Recipient projects & 825 & 650 & 175 \\
Non-recipient projects & 7357 & 6323 & 1034 \\
Successful rate & $10.1 \%$ & $9.3 \%$ & $14.4 \%$ \\
\hline Panel B: Evaluated sample* & & & \\
\hline Proposal evaluated & 5350 & 4498 & 852 \\
Recipient projects & 594 & 459 & 135 \\
Non-recipient projects & 4699 & 4039 & 717 \\
Successful rate & $14.9 \%$ & $10.2 \%$ & $15.8 \%$ \\
\hline
\end{tabular}

Notes: Distribution of program winners on our evaluated sample of countries: DE, ES, FI, FR, IR, IT, NL, NO, SE, UK.

Table A.2. Comparison Matched and Non-Matched: Phase 1

\begin{tabular}{lccc}
\hline \hline & Phase 1: Matched & Phase 1: Non-Matched & SD Differences \\
\hline DE & 0.043 & 0.174 & -0.428 \\
ES & 0.286 & 0.197 & 0.208 \\
FI & 0.050 & 0.034 & 0.079 \\
FR & 0.047 & 0.084 & -0.152 \\
UK & 0.165 & 0.163 & 0.004 \\
IE & 0.043 & 0.045 & -0.007 \\
IT & 0.214 & 0.208 & 0.015 \\
NL & 0.065 & 0.028 & 0.176 \\
NO & 0.031 & 0.017 & 0.092 \\
SE & 0.056 & 0.028 & 0.138 \\
$0-09$ & 0.003 & 0.012 & -0.099 \\
1 & 0.034 & 0.006 & 0.204 \\
2 & 0.231 & 0.151 & 0.204 \\
3 & 0.072 & 0.052 & 0.080 \\
4 & 0.075 & 0.087 & -0.044 \\
5 & 0.025 & 0.012 & 0.099 \\
6 & 0.134 & 0.244 & -0.282 \\
7 & 0.391 & 0.360 & 0.062 \\
8 & 0.028 & 0.047 & -0.096 \\
9 & 0.006 & 0.029 & -0.173 \\
Age & 10.695 & 9.155 & 0.125 \\
Group & 0.572 & 0.669 & -0.198 \\
High-Tech Manufacturing & 0.075 & 0.039 & 0.154 \\
High-Tech Services & 0.306 & 0.433 & -0.263 \\
\hline Observations & 346 & 178 & \\
\hline
\end{tabular}

Notes: This table presents summary statistics for matched recipient firms (Phase 1) to Amadeus in column (1) and recipient firms with missing information on Amadeus in column (2). Column (3) reports mean standardized differences between these two samples. 
Table A.3. Comparison Matched and Non-Matched: Phase 2

\begin{tabular}{lccc}
\hline \hline & Phase 2 & Phase 2: Non-Matched & SD Differences \\
\hline DE & 0.126 & 0.140 & -0.038 \\
ES & 0.241 & 0.140 & 0.259 \\
FI & 0.046 & 0.047 & -0.002 \\
FR & 0.057 & 0.233 & -0.508 \\
GB & 0.230 & 0.140 & 0.232 \\
IE & 0.034 & 0.023 & 0.066 \\
IT & 0.080 & 0.093 & -0.044 \\
NL & 0.115 & 0.093 & 0.071 \\
NO & 0.011 & 0.000 & 0.151 \\
SE & 0.057 & 0.093 & -0.133 \\
$0-09$ & 0.012 & 0.000 & 0.152 \\
1 & 0.023 & 0.023 & 0.000 \\
2 & 0.326 & 0.163 & 0.382 \\
3 & 0.012 & 0.023 & -0.088 \\
4 & 0.081 & 0.023 & 0.261 \\
5 & 0.000 & 0.023 & -0.215 \\
6 & 0.163 & 0.279 & -0.280 \\
7 & 0.314 & 0.372 & -0.121 \\
8 & 0.070 & 0.093 & -0.084 \\
Age & 12.471 & 8.023 & 0.442 \\
Group & 0.655 & 0.605 & 0.103 \\
High-Tech Manufacturing & 0.103 & 0.000 & 0.477 \\
High-Tech Services & 0.333 & 0.395 & -0.127 \\
\hline Observations & 87 & 43 & \\
\hline
\end{tabular}

Notes: This table presents summary statistics for matched recipient firms (Phase 2) to Amadeus in column (1) and recipient firms with missing information on Amadeus in column (2). Column (3) reports mean standardized differences between these two samples.

Table A.4. R\&D Grant Assigment Probability

\begin{tabular}{|c|c|c|c|c|}
\hline \multirow[b]{2}{*}{ Dependent variable: } & \multicolumn{2}{|c|}{ Phase 1} & \multicolumn{2}{|c|}{ Phase 2} \\
\hline & (1) Before Matching & (2) After Matching & (3) Before Matching & (4) After Matching \\
\hline \multirow[t]{2}{*}{ Age } & $-0.026 * * *$ & -0.003 & $-0.035 * * *$ & -0.007 \\
\hline & $(0.008)$ & $(0.010)$ & $(0.015)$ & $(0.022)$ \\
\hline \multirow[t]{2}{*}{ Size } & $0.149 * *$ & 0.089 & $0.545 * * *$ & 0.005 \\
\hline & $(0.069)$ & $(0.085)$ & $(0.124)$ & $(0.173)$ \\
\hline \multirow[t]{2}{*}{ Intangible Assets } & 0.009 & -0.005 & $0.057 * *$ & -0.012 \\
\hline & $(0.016)$ & $(0.021)$ & $(0.028)$ & $(0.037)$ \\
\hline \multirow[t]{2}{*}{ Tangible Assets } & -0.052 & -0.016 & -0.068 & -0.009 \\
\hline & $(0.040)$ & $(0.049)$ & $(0.051)$ & $(0.092)$ \\
\hline \multirow{2}{*}{ Patent Stock } & 0.045 & -0.016 & $0.132 * *$ & -0.055 \\
\hline & $(0.052)$ & $(0.109)$ & $(0.052)$ & $(0.047)$ \\
\hline Country FEs & Yes & Yes & Yes & Yes \\
\hline Industry FEs & Yes & Yes & Yes & Yes \\
\hline Obs. & 37,570 & 5,680 & 34,634 & 1,520 \\
\hline Pseudo $R^{2}$ & 0.30 & 0.01 & 0.25 & 0.04 \\
\hline
\end{tabular}

Notes: Columns (1) and (3) provide the estimates before the nearest-neighbor propensity score matching, while columns (2) and (4) provide re-estimates after the nearest-neighbor propensity score matching. Standard errors are clustered at the firm level. $* * p<0.05, * * * p<0.01$ 
Table A.5. Selection on Unobservables

\begin{tabular}{|c|c|c|c|c|c|}
\hline \multirow[b]{3}{*}{ Restricted Controls } & \multirow[b]{3}{*}{ Full Controls } & \multicolumn{2}{|c|}{ Phase 1} & \multicolumn{2}{|c|}{ Phase 2} \\
\hline & & Patent & Appl & Patent & Appl \\
\hline & & (1) & (2) & (3) & (4) \\
\hline None & Age, Industry & -69.5 & 48.4 & 2.3 & 1.7 \\
\hline None & Age, Age Squared, Industry, Patent Stock & 102.5 & 17.3 & -2.9 & 1.7 \\
\hline
\end{tabular}

Notes: This table shows the delta ratios for the Oster test via OLS. Each cell in the table corresponds to the degree of selection on the unobservables compared to the degree of selection on the observables that would be necessary to explain the results $(\beta=0)$. Each delta corresponds to a comparison of the coefficient estimated in columns (1) and (2) of the Table 3. The full set of controls includes age and the two-way interaction between year and industry dummy variables, followed by age, age-squared, lagged patent stock, and the two-way interaction between year and industry dummy variables.

Table A.6. Anticipation Effects

\begin{tabular}{|c|c|c|c|c|c|c|}
\hline \multirow{2}{*}{$\begin{array}{l}\text { Dependent Variable } \\
\text { Drop: }\end{array}$} & \multicolumn{3}{|c|}{ Patent } & \multicolumn{3}{|c|}{ Appl } \\
\hline & (1) 2013 & (2) 2014 & (3) 2013-2014 & (4) 2013 & (5) 2014 & (6) 2013-2014 \\
\hline \multirow{3}{*}{ Recipient $\times$ Post-Grant } & \multicolumn{6}{|c|}{ Panel A. Phase 1} \\
\hline & $0.641 * *$ & $0.588^{* * *}$ & $0.672 * *$ & $0.695 * *$ & $0.649 * *$ & $0.693 * *$ \\
\hline & $(0.293)$ & $(0.287)$ & $(0.324)$ & $(0.322)$ & $(0.326)$ & $(0.335)$ \\
\hline Obs. & 1,472 & 1,479 & 1,240 & 1,454 & 1,461 & 1,221 \\
\hline \multirow{3}{*}{ Recipient $\times$ Post-Grant } & \multicolumn{6}{|c|}{ Panel B. Phase 2} \\
\hline & 0.782 & 0.594 & 0.449 & 0.495 & 0.240 & -0.075 \\
\hline & $(0.608)$ & $(0.730)$ & $(0.718)$ & $(0.755)$ & $(0.749)$ & $(0.841)$ \\
\hline Obs. & 436 & 437 & 371 & 405 & 406 & 344 \\
\hline Firm FEs & Yes & Yes & Yes & Yes & Yes & Yes \\
\hline Time FEs & Yes & Yes & Yes & Yes & Yes & Yes \\
\hline
\end{tabular}

Notes: This table presents estimates for the R\&D grant effect on innovation performance from specification (2) on a subsample that exclude pre-intervention years. Standard errors are clustered at the firm level for the Poisson estimator and bootstrapped at the firm level with 200 replications for logit estimator. $* p<0.1, * * p<0.05$, $* * * p<0.01$

Table A.7. Additional Robustness Tests

\begin{tabular}{|c|c|c|c|c|c|c|}
\hline "Dependent variable: & (1) Patent & $\overline{~(2) ~ A p p l}$ & (3) Patent & $\overline{\text { (4) Appl }}$ & (5) Patent & 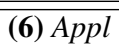 \\
\hline \multirow{3}{*}{ Recipient $\times$ Post-Grant } & \multicolumn{6}{|c|}{ Panel A. Phase 1} \\
\hline & $0.518^{* *}$ & $0.521^{*}$ & $0.527^{*}$ & 0.472 & $0.508^{* *}$ & $0.490 *$ \\
\hline & $(0.249)$ & $(0.293)$ & $(0.290)$ & $(0.316)$ & $(0.246)$ & $(0.287)$ \\
\hline Obs. & 1,890 & 1,870 & 1,890 & 1,870 & 1,890 & 1,870 \\
\hline \multirow{3}{*}{ Recipient $\times$ Post-Grant } & \multicolumn{6}{|c|}{ Panel B. Phase 2} \\
\hline & 0.537 & 0.733 & 0.107 & 0.519 & 0.478 & 0.656 \\
\hline & $(0.323)$ & $(0.680)$ & $(0.344)$ & $(0.695)$ & $(0.309)$ & $(0.693)$ \\
\hline Obs. & 550 & 520 & 550 & 520 & 550 & 520 \\
\hline Firm FEs & Yes & Yes & Yes & Yes & Yes & Yes \\
\hline Time FEs & Yes & Yes & Yes & Yes & Yes & Yes \\
\hline Country $\times$ Time FEs & Yes & Yes & No & No & Yes & Yes \\
\hline 2-digit Industry $\times$ Time FEs & No & No & Yes & Yes & Yes & Yes \\
\hline
\end{tabular}

Notes: This table presents estimates for the R\&D grant effect on innovation performance controlling for additional fixed effects. Columns (1-2) include country-by-year fixed effects to the baseline specification. Columns (3-4) include two-digit industry-by-year fixed effects. Columns (5-6) include country-two-digit industry-by-year fixed effects. Standard errors are clustered at the firm level for the Poisson estimator and bootstrapped at the firm level with 200 replications for logit estimator. $* p<0.1, * * p<0.05$ 


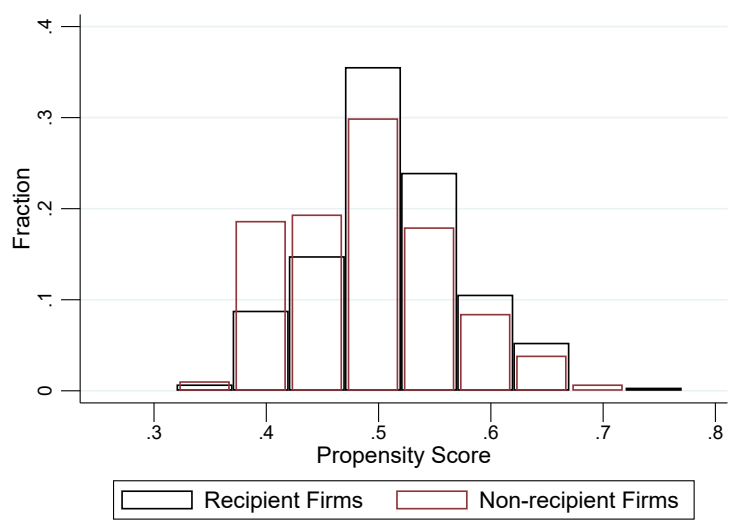

(A) Phase 1

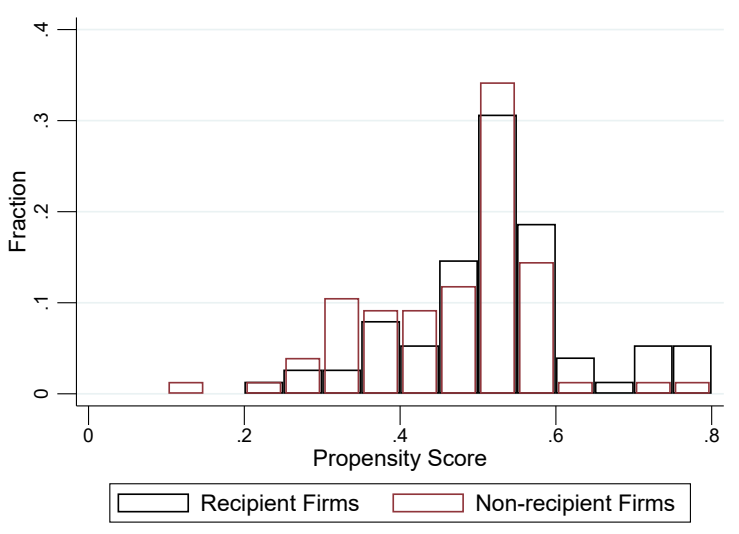

(B) Phase 2

Figure A.1. Propensity Score Distributions.

Note: This figure shows the estimated propensity score distributions across Phase 1 and 2 obtained using nearest-neighbor propensity score matching within common support assumption. 